\title{
Hacia una sociología evolucionista de la revolución
}

\author{
Álvaro Espina \\ Universidad Complutense \\ alvaroespina@telefonica.net
}

RESUMEN

El trabajo revisa la secuencia de las cuatro «generaciones» de teorías sociológicas de la revolución, contemplándola como un proceso de selección histórico-natural del conocimiento mejor adaptado a su objeto. A su vez, la revolución moderna se presenta como el proceso de cambio social evolucionista por excelencia. A través de ella, sin ninguna forma de determinismo, las sociedades tienden a seleccionar en la historia las modalidades de organización social —o «variedades», según Bagehot—que mejor contribuyen al progreso de la civilización, definida ésta como edad post-axial, de acuerdo con Jaspers y Eisenstadt. La mundanización del impulso axial hacia la trascendencia explica el carácter catártico de los procesos revolucionarios modernos y permite distinguirlos de las revoluciones premodernas y de otros procesos formalmente similares. Finalmente, el modelo de elección racional permite contemplar las tres modalidades principales de revolución moderna - liberal, socialista y democrática - bajo un mismo prisma analítico, en el que unas y otras «variedades» revolucionarias aparecen al mismo tiempo como alternativas y como opciones sucesivas, compitiendo todas ellas con el modelo paretiano de circulación de las élites, de carácter también estrictamente evolucionista.

Palabras clave: Revolución, Evolucionismo, Cambio Social, Circulación de las Élites, Sociología del Tiempo, Elección Racional. 


\section{INTRODUCCIÓN}

Una de las contraposiciones más frecuentemente utilizadas en la sociología del cambio social es la antinomia evolución versus revolución ${ }^{1}$. La primera se utiliza como sinónimo de cambio lento, pacífico, difuso, basado en la introducción paulatina de reformas, sin saltos ni cambios radicales; cuando éstos se observan, al comparar momentos distantes en el tiempo, se interpretan como simple resultado de la acumulación de pequeños cambios marginales. Por el contrario, la revolución es sinónimo de cambio rápido, abrupto, que afecta a elementos fundamentales de la cultura y la organización político-constitucional y económica de la sociedad, realizada empleando alguna forma de violencia, y con dirigentes bien definidos. De ahí que una teoría evolucionista de la revolución parezca a primera vista un oxímoron.

En este trabajo hago un uso generoso de algunos conceptos evolucionistas que provienen de la obra de Walter Bagehot Physics and Politics (1872). En su tiempo, todavía un mismo autor se consideraba legitimado para escribir sobre sociología y sobre política monetaria, ya que Bagehot es conocido, sobre todo, por realizar un año más tarde, en Lombard Street, el primer análisis del sistema bancario en el que el mercado del dinero era tratado como el de cualquier otra mercancía. Spencer estableció a priori que las instituciones sociales no surgen bruscamente, sino que son producto de la evolución y «viven antes una existencia subordinada», en forma de ceremonias que aparecen para gobernar la conducta y son manifestación natural de las emociones ${ }^{2}$. En Physics and Politics, Bagehot acometió la tarea de dar una explicación estrictamente evolucionista de la política, asociando el concepto de progreso al de «selección natural de los Estados», aplicando su análisis igualmente a la «selección natural» de los valores, sistemas culturales, formas de gobierno y otras instituciones. Según este enfoque, cuando se contemplan las cosas ex post facto y a largo plazo, los sistemas institucionales que prevalecen se han visto seleccionados «en función de su capacidad para hacer avanzar la civilización» — por muy aleatorio que hubiera sido su origen ${ }^{3}$.

Al igual que afirmara John Stuart Mill de la «originalidad», Bagehot hacía depender el progreso de la innovación —asimilándola analógicamente a la «emergencia de variedades» en el proceso de selección natural de las especies-. Para que se produzca tal emergencia es preciso que el Estado aminore la rigidez derivada de la «torta de costumbres (cake of

\footnotetext{
1 Para un ejemplo de su empleo en el análisis actual, véase «Washington must encourage "evolutionary" rather than "revolutionary" change in Arab lands», http://www.atimes.com/, Front Page Jun 12, 2005.

2 Véase Spencer [1922], §§ 344-346, pp. 14 y 35.

3 Véase mi comentario a su obra en este mismo número de REIS.
} 
custom) y leyes tradicionales» al mínimo imprescindible para mantener unida a la sociedad —dotando a los individuos de status—, eliminando en lo posible toda restricción que impida la innovación -y el contrato-. En ausencia de obstáculos insuperables, la emergencia de «variedades» es el resultado de la tendencia permanente de la naturaleza hacia el cambio (hacia la diversificación de formas y la entropía, en palabras de N. Georgescu Roegen $)^{4}$, de la que deriva el progreso.

La forma natural que han encontrado las sociedades modernas para facilitar esta diversificación, conciliando orden y progreso, no es otra que la discusión libre. Partiendo de la idea de Bagehot, el pragmatismo norteamericano haría enseguida de este concepto el fulcro de sus teorías social y del conocimiento, que llegan hasta la filosofía política actual a través de las teorías de la acción comunicativa y de la democracia deliberativa de J. Habermas ${ }^{5}$. Sofocarla significa asfixiar el progreso, porque, para Bagehot, éste no es otra cosa que «la evolución social desde lo uniforme a lo multiforme», o, más bien, «desde la homogeneidad incoherente hacia la heterogeneidad coherente», como había señalado Herbert Spencer en $1857^{6}$. Con independencia de las enormes carencias del darwinismo social, en este caso se trata de una formulación relativamente frecuente en la investigación sociológica actual desarrollada a partir de las denominadas ciencias de la complejidad.

Pues bien, en cierto sentido, las grandes revoluciones modernas actuaron al modo de válvulas de seguridad allí donde el sistema político trató de bloquear la diversificación de «variedades" y asfixiar el proceso evolutivo y el aumento paulatino de la complejidad social. Naturalmente, esto no ocurrió al modo determinista, sino que sólo sucedió allí donde la aparición de nuevos «recursos de poder» dio lugar a la emergencia de élites sociales económicas y políticas diferenciadas y en donde el Estado y los poderes establecidos trataron de bloquear el acceso paulatino de éstas a las instituciones y a las posiciones dirigentes, de acuerdo con la teoría de «la circulación de las élites», de Vilfredo Pareto.

Esto es, la revolución no es un mero fenómeno tectónico o explosivo —al estilo del estallido volcánico-, ya que toda situación revolucionaria implica agencia y —a diferencia de otras formas explosivas de manifestación de la conducta colectiva, estudiadas por Tilly-

\footnotetext{
4 Véase su obra The Entropy Law and the Economic Process, Cambridge (1971).

5 Véase una síntesis de su trabajo en Fernando Vallespín (2001). Para su relación con el Pragmatismo, véanse Matthew Festenstein (2004) y Larry Ray (2004).

6 Para los nexos entre evolucionismo y pragmatismo, véase el todavía imprescindible Richard Hofstadter (1955). Para la formulación de Spencer (1852 y 1857), véase mi introducción a Textos Clásicos en este número de REIS.

7 Véase Charles Tilly (1978).
} 
para merecer este calificativo requiere la aparición de grupos que asuman la condición de pretendientes a la titularidad del poder. Esto no quiere decir que la causa de la revolución sea exclusivamente la acción conspirativa de tales grupos, como suele aducir el pensamiento reaccionario. Paradójicamente, sin embargo, en la formulación clásica de este pensamiento, establecida por Joseph de Maistre, tal cosa no implicaba agencia, ya que los líderes revolucionarios actuarían como simples marionetas movidas por la Providencia, como castigo a la soberbia del hombre, al rebelarse con su razón contra las leyes divinas inexorables, reveladas a través de la mente colectiva e incorporadas a cada tradición:

«Cuanto más de cerca se examina a las personas aparentemente más activas de la Revolución, más claramente se observa en ellas algo de pasivo y mecánico. Nunca se repetirá lo suficiente que no son los hombres quienes dirigen la revolución; es la revolución la que utiliza a los hombres. Con toda razón se afirma que la Revolución funciona por sí sola. Esta frase significa que en ningún suceso humano se ha revelado la Divinidad con mayor claridad. Y si emplea los instrumentos más viles, es para regenerarnos a través del castigo ${ }^{8}$.

Por el contrario, la sociología de la revolución establece que la causa última de ésta hay que buscarla, en muchos casos, en la incapacidad del Estado para asumir la heterogeneidad y las «variedades» que conducen al progreso. En este sentido, las revoluciones han actuado frecuentemente al modo de correctores evolucionistas de la acción irracional del monarca y las minorías dirigentes que, en palabras de Maquiavelo, «no conocían su verdadero interés», ya que éste (tal como aparece en El Príncipe) coincide siempre con el del principado (estudiado en los Discorsi). Recientemente, Kasperen ha interpretado la construcción de la nación democrática como el mejor ejemplo de éxito de aquella astucia de la razón maquiaveliana, presentando la historia de la democratización de Dinamarca como el resultado de un «programa oculto» del Príncipe absolutista, que, al implantar la conscripción obligatoria para la defensa del territorio, puso en marcha la maquinaria de socialización que aglutinó a la nación moderna y la llevó - a través de un proceso estrictamente evolucionista- hacia la democracia constitucional ${ }^{9}$. En este sentido, muchas revoluciones han servido para corregir la ignorancia de los príncipes que no disponían de un adecuado «programa oculto».

En el continente europeo, ésta ha sido la principal carencia y característica distintiva del modelo de modernización latino, por contraposición a los modelos anglosajón o alemán y

8 Véase Joseph de Maistre (1797), cap. I, in fine. Un comentario, en Berlin (1960). También, Lively (1965), p. 16.

9 Véase Lars Bo Kasperen (2004). 
nórdico, mucho más proclives a anticipar el cambio y a acomodar a las nuevas élites ${ }^{10}$. Por el contrario, en el modelo latino - y en el de Europa Oriental — la renuencia de los sectores dirigentes al cambio social ha embalsado históricamente las aspiraciones de las capas sociales emergentes hasta que éstas alcanzaron masa crítica y se convirtieron en revolucionarias, porque los cambios eran ya de tal intensidad y tan generalmente compartidos que resultaban incompatibles con la totalidad de las instituciones preexistentes, haciendo inevitables las revoluciones, que adoptaron como bandera hacer realidad la materialización de los grandes conceptos, universales e indivisibles, que tanto asustaban a De Maistre — aunque también a Hume y a Bentham-. A su vez, la forma de perseguir tales propósitos adoptó la apariencia de un caos incontrolable que destruía la sociedad, ratificando a los sectores tradicionalistas en su actitud de rechazo compulsivo frente al más mínimo cambio.

Aunque los sectores críticos de estas sociedades llegaron a considerar las revoluciones como la única forma posible de cambio social —poniendo como ejemplo los resultados revolucionarios en los que del caos emergía finalmente un nuevo orden, mucho más dinámico, eficiente y equitativo o, simplemente, como consecuencia de un problema de trascendentalismo expresivo, y hasta estético ${ }^{11}$ - , al final del siglo $\mathrm{xx}-\mathrm{O}$, más bien, del siglo corto que transcurre entre la revolución soviética y la desaparición de la URSS - la valoración de las revoluciones era ya generalmente negativa, dejando paso a otras formas de concebir el cambio y la asimilación de la heterogeneidad social ${ }^{12}$. Ya veremos, sin embargo, que esto es así sólo porque el resultado final de las grandes revoluciones modernas es hoy considerado universalmente como elemento incuestionable de la civilización.

Las ciencias de la complejidad ayudan a comprender mejor las consecuencias del cierre de ciertas sociedades a la fertilización derivada de la heterogeneidad de iniciativas individuales, frente al monopolio de la innovación en manos del Estado — bajo la forma de tradicionalismo, rigidez regulatoria o planificación económica-. Esto no es otra cosa que la respuesta conservadora a la angustia que produce la presencia de lo diferente, lo extraño, que es, en palabras de Robert Michels, «el representante de lo desconocido, o sea, del mundo exterior a lo "familiar", estructurado por las tradiciones que identifican a la colectividad", y que permiten distinguir entre insiders y outsiders; entre los que la comparten y los

\footnotetext{
10 Véase Josep M. Colomer (2001), y mi crítica en Revista Española de Ciencia Política (2001b). La referencia clásica es Tocqueville, L’Ancien Régime et la Révolution.

11 La expresión de tal sensibilidad puede verse en Dany Cohn-Bendit (1986) y en toda la sociología de Bourdieu.

12 Piotr Sztompka (1995). Esto es así incluso para los revolucionarios: véase Ernesto Cardenal, «Las mejores revoluciones son las pacíficas y democráticas, libres y sin imposición alguna»; «La revolución es evolución acelerada», 08.10.2004, http://www.deutsche-welle.de/dw/article/0,1564,1353095,00.html.
} 
que no la siguen, proporcionando un medio de identidad personal y colectiva que se identifica con la aspiración a la trascendencia. Esa identidad dota al individuo de seguridad ontológica, preservando la continuidad en la percepción de su propio yo a lo largo del tiempo y del espacio, especialmente cuando el tiempo se acelera, comprimiéndose -como sucede en la revolución-, y/o el espacio se ensancha y entra en contacto con otras identidades ${ }^{13}$.

El trabajo consta de cuatro partes. La primera contempla la revolución como una confluencia de escalas de tiempo y la analiza de acuerdo con la teoría de la deprivación o frustración de expectativas de Ted Gurr. La segunda presenta los análisis de la tercera generación de teorías de la revolución, fijándose especialmente en el contraste entre los enfoques de Theda Skocpol y Shmuel N. Eisenstadt. La tercera adopta el concepto de ruptura de la era Axial de este último como hilo conductor para recorrer las grandes revoluciones de la modernidad, y enlaza con la forma en que se aborda actualmente el fenómeno revolucionario aplicando técnicas de teoría de juegos y modelos de elección racional. En la cuarta parte, la teoría de la circulación de las élites se toma como punto de partida para presentar el modelo de cooptación de Bertocchi y Spagat a modo de teoría integradora de las tres grandes líneas revolucionarias de la modernidad: las revoluciones liberal, socialista y democrática. Las líneas finales sintetizan el argumento evolucionista y concluyen.

\section{LA DIFERENCIA DE ESCALAS DE TIEMPO (REVOLUCIÓN VERSUS REFORMA) EN LA SEGUNDA GENERACIÓN DE TEORÍAS DE LA REVOLUCIÓN}

En realidad, las grandes revoluciones modernas significaron la irrupción de una nueva escala de tiempo en la que la historia se condensa, la cadencia de los acontecimientos se precipita, y las pautas temporales por las que había venido discurriendo la existencia de los diferentes grupos sociales confluyen — tras haberse ignorado secularmente-, al verse unos y otros forzados a jugarse el todo por el todo de su propia existencia colectiva, como le sucediera al fanfarrón de la fábula de Esopo, cuando se le conminó: «hic Rhodus, hic saltus»14.

Esta interferencia de escalas de tiempo es común a otros procesos de cambio económico y social. Richard Day y Jean-Luc Walter ${ }^{15}$ modelizaron el proceso de crecimiento eco-

\footnotetext{
13 Anthony Giddens (1997).

14 Véase el comentario de Isaiah Berlin en http://berlin.wolf.ox.ac.uk/lists/quotations/quotations_by_ib.html.

15 Véase Richard H. Day y Jean-Luc Walter (1989).
} 
nómico haciendo interactuar matemáticamente pautas de fluctuación sencillas, en una escala de tiempo, con pautas más complejas en otras escalas. Algo similar ocurre en la vida real cuando observamos la superposición de una serie de generaciones coetáneas en un mismo momento del tiempo, supuestamente absoluto, pero cuyos tiempos relativos son también divergentes porque sus memorias - y visiones del mundo- se encuentran divididas, al referirse a distintas experiencias vitales, y sus intereses correlacionados sólo en el interior de cada grupo de cohortes, cuyo comportamiento cambia entre generaciones - a las que el Estado democrático de bienestar obliga a hacer transferencias intertemporales ${ }^{16}$.

Borges trató el asunto bajo la forma de una especie de lotería, de inspiración pitagórica y platónica, en la que la condensación del tiempo adopta la forma de la vieja aporía de Zenón:

«... una intensificación del azar. Una periódica infusión del caos en el cosmos... Tal es el esquema simbólico. Ninguna decisión es final, todas se ramifican en otras. Los ignorantes suponen que infinitos sorteos requieren un tiempo infinito: en realidad basta que el tiempo sea infinitamente subdivisible, como lo enseña la famosa parábola del Certamen con la Tortuga. Esa infinitud condice de admirable manera con los sinuosos números del Azar y con el Arquetipo Celestial de la Lotería, que adoran los platónicos» ${ }^{17}$.

Hanns-Geog Brose expresa ahora esa misma idea afirmando: «El tiempo importa; en estos últimos decenios, quizás más que nunca: el mayor reto de nuestra sociedad es precisamente la diversidad de tiempos diferentes; desacoplados; no sincronizados, correspondientes a sistemas sociales que avanzan a distinto paso y ritmo; la aparición de una cultura de la no-simultaneidad» ${ }^{18}$. ¿Es por fin la teoría de la relatividad aplicada a la noosfera? ¿O se trata más bien de la teoría del caos y de la complejidad estrictamente probabilística? DeLillo lo expresa plásticamente, apropiándose literariamente de la idea del big-bang para aplicarla a la globalización cibernética y financiera:

«Cosmópolis es una novela apocalíptica y el Apocalipsis lo provoca una sola persona, haciendo grandes movimientos de capital en la bolsa por medio de un ordena-

\footnotetext{
16 Véase Berhard Giesen (2004). Para las diferencias de comportamiento en relación a la propiedad de la vivienda de las generaciones obreras alemanas nacidas en 1930, 1940 y 1955, véase Karin Kurz (2004).

17 Borges (1941), p. 459.

18 Véase Hanns-Geog Brose (2004), pp. 7 y 22-23.
} 
dor. En la novela el tiempo se contrae, condensando toda la vida del protagonista en el transcurso de un solo día»19.

La «primera generación» de teorías de la revolución —aparecidas durante los primeros cuarenta años del siglo xx- se centró más en la descripción del hecho revolucionario y de los acontecimientos históricos relacionados con él que en la teoría sociológica propiamente dicha. Contó con las aportaciones de Pitrim A. Sorokin y Crane Brinton a la «sociología» (1925) y a la «anatomía» (1938) de la revolución, junto a otras que estudiaron su «sicología», su «proceso» o su «historia natural».

En cambio, la denominada «segunda generación» de estas teorías, formuladas entre 1940 y $1975^{20}$, hizo énfasis precisamente en el carácter disruptivo en el tiempo de las nuevas pautas de acontecimientos que dan lugar a los grandes procesos revolucionarios. Según estas teorías, un estado potencialmente revolucionario aparece cuando el efecto de tales rupturas sobre una serie de variables clave — como el «estado mental» de las masas, el «equilibrio de los sistemas sociales» o el conflicto de intereses entre clases - alcanza intensidad suficiente. En este punto, sólo una acción decidida de las élites dirigentes en orden a restablecer el equilibrio de la variable crítica podría evitar la revolución, lo que implica acometer reformas de gran calado o elevar sustancialmente el nivel de represión.

Un subconjunto de estas teorías analiza la revolución en términos de psicología cognitiva como respuesta a situaciones de frustración o deprivación relativa de las expectativas colectivas respecto a la consecución de algún tipo de fines, sean éstos de tipo cultural o económico. El modelo general más conocido de esta forma de análisis se debe a Ted Gurr $-\mathrm{y}$ antes a Sorokin ${ }^{21}$ y adopta la forma del diagrama I, en el que el impacto de la variable «deprivación» sobre la variable «antagonismo civil» se ve intermediado por cuatro factores: el nivel de coacción ejercido desde el poder, su grado de institucionalización, el nivel de «retribución» que alcanza la disidencia (que puede especificarse en términos de ciertas «facilidades estructurales» para el hecho revolucionario y/o en la existencia de un clima de opinión tendente a la aceptación social del mismo) y la mayor o menor legitimación del poder establecido, de los cuales sólo el tercero produce un efecto amplificador (su coeficiente tiene signo positivo), mientras que los otros tres atenúan el conflicto (sus coeficientes tienen signo negativo).

\footnotetext{
19 En entrevista a Babelia, El País, 24-XII-2004.

20 Véase Jack A. Goldstone (1980).

21 Véanse Ted Gurr (1968) y Sorokin (1937).
} 
DIAGRAMA I

El modelo inicial de Ted Gurr

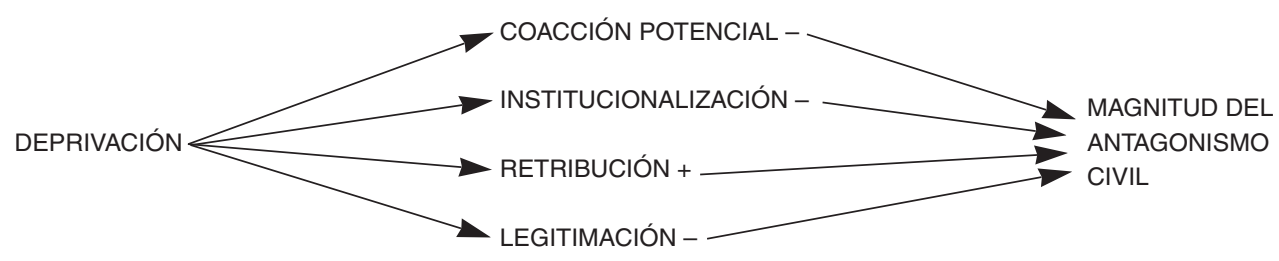

El contraste empírico del modelo con los datos disponibles en 1968 para 114 países permitió a Gurr confirmar que los indicadores de deprivación relativa —esto es, las variables psicológicas indicativas de un estado mental colectivo de frustración de expectativas- explicaban dos tercios de la varianza de los indicadores de disidencia y conflicto. El efecto resultaba directo cuando se trataba de situaciones de deprivación relativa estructural y persistente, pero en las situaciones de frustración percibidas a corto plazo se veía parcialmente contrarrestado por el nivel de la fuerza represiva y considerablemente amplificado por las facilidades estructurales y el grado de aceptación social (la «retribución»).

En cambio, la percepción de legitimidad del poder, en lugar de actuar como variable de intermediación —como preveía la hipótesis inicial—, se comportaba como una variable con un cierto efecto directo, aumentando la propensión hacia la disidencia cuando el poder era considerado ilegítimo, y también con efecto indirecto, aunque desplegado en este caso a través de su impacto sobre la capacidad para elevar el potencial coactivo del régimen. Además, el grado de institucionalización de los cuerpos intermedios de la sociedad no se interponía directamente entre la deprivación y el antagonismo, sino que actuaba, a su vez, influyendo sobre la capacidad coactiva del poder y sobre la «retribución» del conflicto. Esta última era en realidad la única variable intermedia en sentido estricto, al condicionar las decisiones tácticas de los individuos y grupos a la hora de tomar la decisión de participar en el conflicto, mientras que todas las demás variables actuaban, de uno u otro modo, a través de ella. Esto es, el modelo de Gurr realzaba extraordinariamente el carácter de la revolución como momento culminante de la acción social, considerando a ésta impulsada por estímulos «racionales», aunque colectivos, de acuerdo con la teoría de los incentivos.

Por otra parte, la persistencia del conflicto a lo largo del tiempo influía sobre el conflicto actual (lo que se midió a través del impacto de los indicadores de conflictividad en 1946-1959 sobre los de 1961-1965), pero también de forma indirecta, fortaleciendo el nivel de aceptación y aumentando la probabilidad de la decisión de participar. Finalmente, la fuerza coac- 
tiva potencial incidía sobre la decisión estratégica de los individuos de acuerdo con una función que tenía forma de $U$, de modo que con baja capacidad de coerción el nivel de conflictividad era elevado; la violencia se aminoraba sólo a partir del punto en que la fuerza coactiva alcanzaba una cierta masa crítica, pero un nivel excesivo de coerción volvía a disparar la conflictividad, haciendo bueno el dicho según el cual «más vale maña que fuerza». Nótese en todo ello el papel evolucionista que desempeña el conflicto revolucionario en el modelo de Gurr, penalizando a los sistemas sociales incapaces de evitar la deprivación, de organizar adecuadamente sus sistemas coactivo e institucional y de alcanzar un nivel suficiente de legitimidad 22 .

Las críticas a este conjunto de teorías han sido múltiples. La que afecta más directamente al modelo de Gurr se refiere a la omisión de variables relevantes al utilizar indicadores de carácter macroscópico para materializar la variable crítica —en este caso la deprivación-, en lugar de emplear indicadores microsociales del estado cognitivo de los individuos. Según Goldstone, esta técnica sólo permitiría demostrar la correlación entre los cambios macrosociales y la intensidad del conflicto, pero no entre esta última y la percepción individual de deprivación o el estado cognitivo de las masas. Existiría, pues, un error grave de especificación. Ahora bien, Gurr construye sus seis indicadores compuestos de «deprivación persistente» y sus siete indicadores de «deprivación a corto plazo» (cinco económicos y dos políticos), empleando para ello 48 variables de segmentación social, discriminación por colectivos y restricciones a la movilidad económica y educativa, de intolerancia y discriminación religiosa y de compartimentación y adscripción en la determinación de las élites políti$\operatorname{cas}^{23}$.

A la vista de la amplísima cobertura que proporciona este conjunto de variables respecto a las posibles causas de percepción cognitiva de deprivación por parte de las masas, aquella crítica parece excesivamente severa porque el conjunto de variables proxy resulta a todas luces consistente para construir tales indicadores, de acuerdo con las mejores prácticas adoptadas por la investigación sociométrica más reciente. Además, la crítica resulta en cierto modo ucrónica en lo que se refiere a la metodología, ya que en 1968 ni las técnicas microeconométricas ni las facilidades de cálculo computacional habían alcanzado todavía el desarrollo que alcanzarían en los ochenta.

Podría decirse que al análisis de Gurr le restaba por probar el nexo exacto entre una situación evidente de deprivación multidimensional y la percepción cognitiva individual acerca de tal estado. No es menos verdad que en tal caso la carga de la prueba a contrario debe-

22 Ted Gurr (1968), figuras 2 y 3.

${ }^{23}$ Para la crítica de Jack A. Goldstone (1980), p. 431. Para la construcción de las variables de Ted Gurr (1968), pp. $1109-1112$. 
ría recaer sobre quien argumenta que un estado social objetivo de deprivación, detectado a través de tal masa de evidencia, no resulta perceptible por quienes lo soportan de forma persistente y/o en breves períodos de tiempo — pudiendo compararlo en este último caso con un estado precedente menos carencial, tras haber disfrutado o anticipado expectativas más halagüeñas, lo que aumenta la probabilidad de ocurrencia revolucionaria, de acuerdo con el análisis de Davies (1962) —. Para ello habría que apelar a algún tipo de obstáculo cognitivo —distinto al habitualmente utilizado por las escuelas de los «maestros de la sospecha», que suelen apoyarse sobre velos ideológicos nunca definidos con precisión-, definirlo y demostrar su operatividad, aportando la correspondiente evidencia empírica. Mientras esto no se haga, las conclusiones de Gurr pueden considerarse todavía científicamente aceptables ${ }^{24}$.

Otro juicio merecerían las críticas a los análisis, comprendidos también dentro de esta «segunda generación de teorías», en que la variable crucial se refiere a alguna forma de «desequilibrio de sistemas» 25 — como los que se suponen derivados de la revolución demográfica o del proceso de urbanización-, en cuyo caso la objeción de Goldstone resulta justificada porque la hipótesis de relación entre tales procesos y aquel desequilibrio requiere una especificación adecuada de las variables en que se materializa el desequilibrio y/o alguna variable intermedia entre unas y otras. La otra crítica que parece bien fundada se refiere a la dificultad de concretar el nivel de conflicto y la dinámica por la que una situación de violencia potencialmente revolucionaria se convierte en revolución. Esta crítica afecta especialmente a análisis, como el de Tilly ${ }^{26}$, en que el estallido revolucionario se produce cuando el conflicto de intereses entre clases alcanza un «punto crítico» en que las situaciones de «doble soberanía» no pueden reconciliarse bajo el mismo sistema político.

\section{LA TERCERA GENERACIÓN DE TEORÍAS SOCIOLÓGICAS DE LA REVOLUCIÓN}

Otra de las críticas al racimo de teorías de segunda generación consiste en su olvido del papel desempeñado por la intrusión de escalas de tiempo entre la política y la economía internacionales y la organización de las sociedades que atraviesan por una situación revo-

\footnotetext{
24 Ted Robert Gurr dirige actualmente el Center for International Development and Conflict Management (CIDCM) de la Universidad de Maryland y es el creador del Polity IV Project (Political Regime Characteristics and Transitions, 1800-2003), cuya base de datos proporciona la información básica de muchos de los análisis a los que nos referiremos en el tercer epígrafe (véase http://www.cidcm.umd.edu/inscr/polity/). EI CIDCM es un centro muy activo en la creación y difusión del conocimiento dirigido hacia la lucha por la paz global.

25 Como, por ejemplo, en el caso de Neil Smelser (1963).

26 Véase Charles Tilly (1975).
} 
lucionaria, como factor desencadenante de la misma. De ahí que la tercera generación de teorías de la revolución —formuladas en torno a 1980 - tratase de corregir esta carencia situando como condición necesaria del hecho revolucionario las presiones derivadas de los mercados internacionales y de la competencia entre estructuras militares sobre la organización económica y sobre la extracción de recursos, lo que asimila en cierto modo tales procesos a los de descolonización, aunque se produzcan en países independientes.

Sin embargo, la «tercera generación» volcó sus esfuerzos y puso el mayor énfasis en las precondiciones que dan pie al hecho revolucionario, enfatizando su carácter estructural y desdibujando el carácter de la revolución como proceso privilegiado de la acción social, hasta el punto de que el papel de las élites quedó difuminado con relación a la relevancia que había adquirido para la generación anterior la evaluación de la negativa de aquéllas a proceder a aplicar reformas en tiempo adecuado —o de su acción intempestiva-, como factor desencadenante, impulsor o catalizador del proceso. Por el contrario, el enfoque que se da al estudio de las élites en esta tercera generación adopta también la perspectiva estructural.

La comparación de los diagramas con que Goldstone ${ }^{27}$ sintetiza los análisis de los dos principales representantes de esta corriente analítica - Theda Skocpol y Shmuel N. Eisenstadt- arroja diferencias sustanciales referidas exclusivamente a dos grandes ámbitos:

A. Junto a precondiciones comunes para llegar a la situación revolucionaria, relacionadas con los fines del Estado y con la estructura de las élites, Skocpol considera constante en todas las grandes revoluciones la existencia de estructuras sociales fundamentalmente agrarias; en cambio, la aportación fundamental de Eisenstadt consiste en identificar una «orientación cultural» con fuerte tensión entre lo trascendente y lo mundano como factor recurrente en toda gran revolución, lo que resultaría atribuible al imperativo cultural -ya sea religioso o «natural», en el sentido iusnaturalista - de producir un cambio social «integral» —esto es, de largo alcance, indivisible y simultáneo en las diferentes esferas sociales, connotaciones utópicas incorporadas al concepto de libertad ${ }^{28}$ _, mientras que sociedades en que prevalece una orientación cultural más «intramundana» suelen admitir cambios fragmentarios, realizados paso a paso y con mayor pragmatismo.

B. En lo que se refiere a los factores que condicionan el resultado de las revoluciones, ambos autores otorgan un peso decisivo a la distribución de recursos entre los contendientes, pero difieren en la consideración determinante que otorga Eisenstadt a la situación de aislamiento y cerrazón —o de relación fluida con otras élites y/o grupos periféricos- de

27 Para la crítica de Jack A. Goldstone (1980), figuras 2 y 3, pp. 441 y 445.

28 Veáse Mannheim (1936), pp. 273-275. 
la élite que dirige el proceso, a la hora de orientar el tipo de organización social que emana de la revolución (dictatorial y monopolizadora del poder, en el primer caso; abierta y menos coactiva, en el segundo). Además, en el enfoque de Eisenstadt el fundamentalismo de las élites suele estar asociado con su carácter cerrado, mientras que la orientación intramundana lo está con su carácter abierto 29 .

Estas dos aportaciones selectivas de la tercera generación de analistas del fenómeno revolucionario resultan extraordinariamente significativas, aunque no sirvan para paliar las insuficiencias teóricas y, sobre todo, empíricas de todos aquellos planteamientos, excesivamente estructuralistas. Centrada en el análisis de las grandes revoluciones de Eurasia, la aportación de Theda Skocpol constituye el puente entre la teoría de la revolución y el análisis reciente del impacto de la colonización sobre el desarrollo, al colocar en el centro de la explicación del hecho revolucionario la pretensión de abolir las estrategias de simple extracción de rentas desplegadas tradicionalmente por las élites terratenientes en el viejo mundo -al igual que lo hacían ciertas metrópolis sobre sus colonias_ ${ }^{30}$. Éste fue el objetivo establecido generalmente por las nuevas élites emergentes asociadas a la industrialización, la modernización y la aparición de la empresa capitalista, pero tal pretensión no siempre condujo a situaciones revolucionarias.

Frente a la economía fisiocrática, en la Inglaterra de comienzos del siglo xIx la nueva economía política de David Ricardo proporcionó la teoría para que tal estrategia se llevara a cabo a través de la reforma económica, utilizando como palanca para ello una forma de tributación que gravase sobre todo las rentas improductivas, respetando a los beneficios como fuente para la acumulación de capital, en combinación con una estrategia de reforma parlamentaria que concedió derechos de voto a la élite emergente, ampliándolos muy lentamente. Además, la orientación cultural de los radicales filosóficos era típicamente intramundana y cosmopolita, ya que su criterio moral superior era la mayor felicidad terrena para el mayor número. En otros casos — que no contaron con los precedentes de la revolución parlamentaria inglesa del siglo xVII, con la revolución agrícola, con la larga historia de los cercamientos, ni con los inicios de la revolución industrial del xVIII- no se dispuso de tales estrategias, ni la clase emergente contó con efectivos suficientes para aplicarla, de modo que el único vehículo para romper el maleficio del círculo vicioso de la extracción de rentas resultó ser la revolución liberal, con su secuela de desvinculaciones y desamortizaciones, cuyos resultados dependieron de las características y la capacidad de innovación de las nuevas élites ${ }^{31}$.

\footnotetext{
29 Véanse Theda Skocpol (1979) y Shmuel N. Eisenstadt (1978).

30 Véase Stanley L. Engerman y Kenneth L. Sokoloff (2005).

31 En el caso de España, la revolución liberal preservó la estratificación social del Antiguo Régimen, las nuevas élites se amalgamaron con la antiguas y su estrategia económica fue básicamente rentista. Véase Espina (2000).
} 
Lo sucedido en América ratifica este análisis: allí donde la colonización había producido élites amplias e igualitarias, la independencia produjo los mismos resultados que las grandes revoluciones de la fachada atlántica europea y tuvieron un «rotundo sabor a movimiento social»32, eliminando el núcleo de extracción de rentas, representado en este caso no por la élite nobiliaria, sino por la metrópoli colonial - y no tanto a través de la extracción directa de renta fiscal, como por la reserva de mercado para la expansión de las manufacturas metropolitanas, condición necesaria para la revolución industrial.

En cambio, en aquellas zonas ultramarinas en donde las élites criollas se beneficiaban casi exclusivamente de estrategias extractivas, la independencia sirvió para fundar nuevos regímenes que consolidaron, modernizándolas, las viejas instituciones políticas antiigualitarias, utilizando el ideal de los derechos del hombre y del ciudadano, importado de las revoluciones europeas, como credo fundamentalista, no para articular un cambio de «orientación cultural», sino como envoltura simbólica que permitió lavar la cara a las viejas instituciones coloniales, remozando su discurso de legitimación con el lenguaje de la llustración y con las banderas y la parafernalia del nacionalismo independentista. Éste proporcionó a las élites dirigentes la oportunidad política de conformar una narrativa identitaria fresca y fundacional, aunque cerrada sobre sí misma, perfectamente adaptada a su propia versión de la organización política, capaz de dificultar al mismo tiempo la aparición de otras versiones identitarias en las que la élite criolla pudiera perder la centralidad ${ }^{33}$, lo que apareció con toda claridad en la revolución mexicana, y reaparece ahora bajo la forma de movimientos revolucionarios con un fuerte componente indigenista (Chiapas, Venezuela, Guatemala, Ecuador, Perú y Bolivia) ${ }^{34}$.

El análisis estructuralista de Theda Skocpol constituye el momento culminante y final del tipo de enfoque más firmemente enraizado en la tradición ilustrada, que es el que prevaleció en la sociología occidental hasta 1980, por el que la revolución se concebía fundamentalmente como un arma de la razón — con más o menos ingredientes de astucia o providencialismo teleológico- para abrir paso a las formas de organización social mejor adaptadas al nuevo contexto —o sea, racionales - una vez eliminados los «obstáculos estructurales» apoyados simplemente en la tradición y, por tanto, irracionales.

\footnotetext{
32 Véase Charles Tilly (1997b).

33 Sobre esta relación entre nacionalismo y nuevos estados independientes, véase Charles Tilly (1997a).

34 Véase Thomas Benjamin (2000). También, F. Galdoni, «Los indígenas quieren el poder», El País. Domingo, 19-6-2005, pp. 8-9. Sobre la relación de todo ello con la estrategia ibérica de colonización, véase Espina (2005b).
} 
La complejidad de los procesos revolucionarios puesta de manifiesto por la emergencia de la revolución iraní en 1977-7935 no permitió seguir cerrando los ojos al lado oscuro de la modernidad. La propia Theda Skocpol dedicaría cierta atención a esta vertiente de las revoluciones que, aunque había estado siempre ahí, había sido generalmente ignorada, pero que habría de proliferar a partir de entonces. Cuatro de los estudios recogidos en el volumen recopilatorio de sus trabajos durante el decenio de los ochenta versaron precisamente sobre las revoluciones y los conflictos del tercer mundo, contemplados, sin embargo, como excepciones, y trataron de encontrar el vehículo para abrir paso a la cultura, la ideología, la religión y la acción dentro de un paradigma dominado por los factores estructurales, aunque el marco conceptual se resistiera a encajar el nuevo reto y la autora terminase el libro descalificando estruendosamente a sus críticos, antes de abandonar ella misma el campo de la sociología de la revolución para pasar a la del bienestar, mucho más acorde con la dialéctica del progreso ${ }^{36}$.

En esto consistía, en realidad, la aportación «disidente» realizada por S. N. Eisenstadt a la teoría de las revoluciones en 1978, según la cual el resultado de los procesos revolucionarios depende fundamentalmente de la «orientación cultural» de las élites contendientes por el poder (trascendentalista y fundamentalista versus inmanente y mundana), y a la mayor o menor densidad de sus relaciones con otras élites y grupos sociales (tanto internos como externos). Eisenstadt trataba de reintroducir por esta vía la fenomenología revolucionaria dentro de la problemática de la búsqueda de seguridad ontológica —conceptualizada bajo múltiples denominaciones: religión, filosofía, identidad, raza, clase, nación o civilización.

Pero, al mismo tiempo, detrás del proscenio revolucionario en que se representan movimientos, palabras, procesos y rituales más o menos parecidos aparecía una clara divisoria en el género y en el argumento de la representación. En ambos casos la revolución constituye una forma de acción social propositiva — no un proceso dirigido por ninguna clase de determinismo histórico- - Lo que sucede es que, bajo una fenomenología aparentemente igual, el concepto revolución esconde movimientos contrapuestos, diferenciados precisamente por el fin perseguido por los sujetos de la acción. Probablemente, la mejor ilustración de este carácter ambivalente y dual se encuentre en el análisis de la revolución española durante el reinado de Fernando VII realizado por Miguel Artola ${ }^{37}$.

De acuerdo con la interpretación de Eisenstadt, las grandes revoluciones occidentales habrían sido el vehículo a través del que se abrió paso la creencia radicalmente moderna de

\footnotetext{
35 Véase John Foran (ed.) (1995).

36 Véanse Theda Skocpol (1994) y John Foran (1997).

37 Véase Miguel Artola (1968).
} 
que los seres humanos podían superar el foso infranqueable que había venido separando lo trascendental de lo mundano durante el largo período de la historia de la humanidad al que Jaspers denominara «edad axial», iniciada con la aparición de las grandes religiones durante los seiscientos años que precedieron a la formación del cristianismo.

Durante toda esta «edad», las «civilizaciones axiales» —las religiones monoteístas, el confucianismo clásico, el hinduismo y el budismo- sólo admitieron la posibilidad de superar aquella brecha a través de alguna variedad de gnosis, concebida como una forma misteriosa de mediación entre lo trascendente y lo inmanente, a la que no le era dado al hombre acceder más que a través de un movimiento de carácter místico, religioso, mágico o esotérico, en el que algunos individuos «iniciados» se ven transportados por alguna fuerza superior, independiente de su propia acción o de la colectividad, para recibir la revelación. Es en ese mundo esotérico de valores donde se inserta en última instancia el orden social de la era axial, de modo que su dirección queda confiada a la élite selecta que dispone del carisma que da acceso al bien y a la verdad, explicación acorde con el liderazgo carismático tradicional de Max Weber. En la división de tareas de la sociedad tradicional de Giddens, los guardianes de la tradición son los depositarios e interpretan la verdad, mientras que los gobernantes dan órdenes, aunque su estabilidad a largo plazo depende del "aura" de legitimidad que les proporciona la "sabiduría" de aquéllos ${ }^{38}$.

Dentro de las civilizaciones axiales, las grandes revoluciones significaron el intento supremo de «reconstruir el mundo de lo mundano - la personalidad humana y el orden sociopolítico y económico - con arreglo a los principios de un orden ontológico o ético superior». Pero se trataba de un intento protagonizado por primera vez por seres humanos corrientes, que actuaron reflexivamente, al modo platónico y dialéctico, a través de la acción colectiva. De ahí que la única modernización plena en un país no occidental se llevara a cabo, sin necesidad de revolución, en una civilización no axial ni ideológica —Japón-, apoyándose desde su origen en una capacidad reflexiva autorreferente que permite recrear la comunidad incesantemente a partir del propio pasado ${ }^{39}$.

En cambio, las grandes revoluciones occidentales significaron -y, al mismo tiempo, presupusieron - el descubrimiento de que aquella gran cortadura podía superarse en realidad a través de la acción humana — tanto individual como colectiva-, actuando al modo de un gran movimiento que rompió con el dualismo del imaginario social occidental uniendo, a impulsos de los propios hombres, los dos planos separados —al modo de placas tectóni-

38 Véase A. Guiddens (1997), pp. 107-111.

39 Véanse S. N. Eisenstadt (1996), traducido por la Unesco en http://www.unesco.org/issj/rics151/eisenstadt.htm, y S. N. Eisenstadt (1986). 
cas - que habían venido sirviendo para formar la representación de la realidad: el orden trascendente, que regulaba el imperativo moral y político, y el orden práctico, que se refiere al mundo material y a la división del trabajo. De lo que se trataba era de alcanzar la plena autonomía del individuo — con la vocación de arrastrar al conjunto de la humanidad en pos de los derechos universales del hombre y el ciudadano-, para abandonar definitivamente el mito de Prometeo encadenado. Por esta razón, Eisenstadt considera que la modernidad -primero occidental y más tarde global — significa en realidad la aparición de una nueva civilización ${ }^{40}$, a la que corresponde también un nuevo tipo de instituciones, que rompen radicalmente con las de la era axial —y en el orden político equivalen al Estado laico.

¿Qué es lo que proporcionó el impulso para producir semejante cortadura histórica? Para Max Weber y para Thomas K. Merton, la causa hay que buscarla en el vacío cognitivo provocado por la convicción calvinista según la cual el hombre no puede conocer los designios divinos, lo que produce en el cristiano reformado una inseguridad ontológica y una angustia existencial que le impulsan a buscar en la actividad mundana los signos de la predestinación. Pero ¿es suficiente la inquietud cognoscitiva para explicar semejante paso? Probablemente, no. La antropología del hombre renacentista no hace una separación tan nítida como la del hombre moderno entre lo cognitivo, lo valorativo, lo emocional y hasta lo estético. Después de la seguridad espiritual del Medioevo, por la que el ser humano se percibe confortablemente instalado en una comunidad omnicomprensiva — la cristiandad del Dante-, la fe protestante, al rechazar cualquier imagen antropomorfista de lo divino, deja al hombre del Renacimiento tardío en el aislamiento más radical, produciéndole una triple humillación ontológica: cognitiva (porque no puede conocer su futuro trascendente); emotiva (porque se ve abandonado por un Dios que ya no le ama como un hijo, ni otorga a su pueblo el carácter de elegido), y valorativa (porque ya no puede ganarse la felicidad celestial por medio de sus obras) ${ }^{41}$. Es como si se hubiese producido una segunda expulsión del paraíso terrenal.

Es esa misma crisis de identidad la que se encuentra detrás de la explosión humanista, por la que el hombre mismo se convierte en su propio dios vicario, pasando al primer plano de la imagen cósmica. Como ha sucedido siempre en Occidente, esta percepción había llegado previamente al arte: de una iconografía medieval en la que el hombre aparecía como simple oferente ante la divinidad y su corte celestial, en el retrato renacentista es el individuo quien ocupa el primer plano. La corrupción y la degradación de costumbres de los dignatarios eclesiásticos — que eran, para Maquiavelo, la piedra de escándalo y la causa de impiedad que obstaculizaba la aparición de la virtú cívica entre los italianos— fueron el caldo de cultivo en que germinó la nueva aspiración ontológica e identitaria. La reforma no

40 Véase S. N. Eisenstadt (2001), pp. 320-340 (p. 321).

41 Véase Eduardo Bericat Alastuey (2001). 
hizo más que dar expresión religiosa a un cambio que ya había penetrado en el imaginario emocional de los espíritus más avanzados de la época y en la filosofía erasmista. Pero, al convertirlo en fe religiosa, el protestantismo hizo de aquella percepción vanguardista un sentimiento identitario en el que podía participar el individuo corriente, transformándola en una fuerza de cambio social formidable.

Ésta es la ruptura civilizatoria analizada por Eisenstadt. Para formular su rica elaboración, el gran sociólogo judío partió —como material empírico inicial— del análisis introspectivo de aquella dicotomía en la intrincada trayectoria dualista de las tradiciones gnoseológicas en conflicto dentro de la propia cultura judía, continuando con ello una larga serie de aportaciones arraigadas en esa misma tradición cultural. Entre ellas se encuentra la obra de Isaiah Berlin, quien situó aquel dualismo en el corazón mismo de la llustración, en la que se fragua, junto al mito de la razón, la sistematización del ideal reaccionario ${ }^{42}$. Pero incluso dentro del ramal racionalista, una vez roto el dualismo axial y alcanzada la autonomía inmanente de la acción humana, la radicalización de la modernidad se caracterizaría a partir de entonces por «el desarrollo continuado y la formación, constitución y reconstitución de una multiplicidad de programas culturales», lo que impide la vuelta a cualquier monismo o a la caracterización unitaria y definitiva de la propia modernidad.

La modernidad es, por definición, pluralista, lo que rompe con cualquier pretensión científica estrictamente positivista y determinista, especialmente en lo que se refiere al análisis de las revoluciones fundacionales, e implica partir de la capacidad de los actores sociales para proponer y llevar a cabo transformaciones autónomas de su propia cultura, y, por ende, de las instituciones y la realidad social, a través de movimientos orientados por élites capaces de «articular visiones alternativas del orden social en sus identidades culturales». El pluralismo implica que las fronteras entre las distintas identidades pueden ser impermeables y excluyentes, lo que suele asociarse a una orientación cultural fundamentalista - que conserva adherencias premodernas, o ni siquiera debe considerarse moderna-, pero puede ser también porosa, dialogante e incluyente. Esta última —el cosmopolitismo de la llustración- es la orientación más radicalmente consecuente con la modernidad, pero en modo alguno es la única moderna; también está el lado oscuro, el que condujo al holocausto o al gulag ${ }^{43}$.

Porque la modernidad radical implica romper con cualquier pretensión teleológica y trascendentalista de la historia. El fin de ésta no se encuentra escrito en parte alguna. Todo es

\footnotetext{
42 La formulación clásica, en Lazare (1894). Berlin desarrolló el tema a lo largo de toda su obra, especialmente en (1956), (1960), (1965), (1966) y (1973).

43 Véase S. N. Eisenstadt (2004), p. 392. En general, S. N. Eisenstadt (1999).
} 
prueba y error. Eso no quiere decir que todos lo proyectos sean igualmente válidos: existen criterios de evaluación a priori que permiten minimizar el riesgo, pero la colectividad puede emplearlos o no hacerlo. En última instancia, todo proyecto que logra abrirse paso dispone de una oportunidad limitada para demostrar su acierto. $Y$ ello con independencia de lo tortuosos que hayan podido resultar los procedimientos empleados, ya que la tecnología de adquisición del poder por cualquier grupo pretendiente suele implicar la elaboración de una doctrina, o «credencial mítica», que contiene proporciones variables de verdad y propaganda y resulta relativamente independiente de la evidencia disponible ex ante acerca de su capacidad para producir una organización social más eficiente ${ }^{44}$. Ahora bien, la adquisición del poder tiene carácter instrumental: al término, si se ha prometido mayor felicidad, el grupo deberá proporcionarla. Esta exigencia es tanto más imperiosa cuanto más mundanos y verificables son los objetivos comprometidos. En caso de incumplimiento flagrante, antes o después la colectividad que adoptó un camino equivocado — por comparación con sendas alternativas más venturosas, cuyo conocimiento esté a su alcance- se ve obligada a desandar el camino hasta el punto de bifurcación y seguir los pasos de quienes tomaron la senda más satisfactoria, aprendiendo de su experiencia. El coste del ensayo y el tiempo perdido sirve como aprendizaje a quien se equivocó - $-\mathrm{y}$ a los que vienen detrás- para elegir en lo sucesivo con mayor cautela. Ésa es la senda evolucionista de la revolución.

Por eso, el ensayo de Eisenstadt se halla en las antípodas del análisis de Charles Tilly, orientado por la lógica cartesiana de la investigación racional y por la búsqueda de la verdad científica positiva, que es la que prevaleció como principal rama de la modernidad, con resultados que son generalmente identificados con el progreso, pero que ha inducido con frecuencia al autoritarismo tecnológico y al gobierno de los expertos, porque conserva adheridos ciertos trazos de la edad axial —porque todavía no es plenamente moderna, como diría Giddens-. Apenas tiene cabida en esta orientación el pluralismo constructivista o expresivista, que mantiene aquella misma apertura hacia una cierta verdad trascendental, pero implica una duda todavía más metódica y una mayor disposición a asumir la incertidumbre implícita en la actitud verdaderamente científica, que requiere abandonar definitivamente la seguridad absoluta, propia de las verdades de la edad axial —verdades «formulares», en la terminología de Giddens-, y asumir que el conocimiento no es meramente pasivo, sino que implica también existencia, creatividad, manipulación y acción. Y acción significa también elección, lo que implica riesgo. No resulta extraño, por ello, que la obra original de Eisenstadt fuera acogida por Tilly en 1979 con verdadero sarcasmo:

«El libro Revolution and the Transformation of Societies es un Marbelator abstracto, un argumento sencillo y bien conocido, calafateado con la ayuda de un vasto anda-

44 Barrington Moore, Jr. (1955). 
miaje conceptual... [en lugar de] un cuerpo sistemático de evidencia o de un análisis con detenimiento de cualquier revolución concreta... las abstracciones descansan sobre abstracciones: "Cambios en el ámbito simbólico," dice un párrafo típico, "tienden a erosionar las bases de legitimación del orden social y político"»45.

Y, sin embargo, habría que replicar, éste es el tipo de discurso central de la abducción (o, más bien, de su primer movimiento, la retroducción), que es el proceso mental de innovación creativa para la formulación de hipótesis y teorías definido por Charles Peirce como tercera modalidad de inferencia - distinta de la deducción, que va de la proposición general a la particular, y de la inducción, que parte de la regularidad de asociaciones observada en casos particulares para inferir reglas generales-. Una forma de inferencia que ocupa actualmente «el centro de la noción realista de explicación científica» ${ }^{46}$, especialmente en el campo de las ciencias sociales. En palabras de C. P. Peirce (1903), la abducción es el «primer estadio» de la interpretación (seguida de la deducción y la inducción), ya que busca premisas plausibles «formando hipótesis explicativas». La anticipación abductiva de la «mejor explicación» termina en la dinámica de «fijación de la creencia» (Wirth, 1998, 1999).

\section{LA CUARTA GENERACIÓN DE TEORÍAS SOCIOLÓGICAS Y LA ECONOMÍA POLÍTICA DE LA REVOLUCIÓN}

En lo que se refiere al contenido de la teoría de la revolución, la denominada cuarta generación recuperó durante los años noventa la preocupación por los elementos cognitivos, identitarios, de agencia consciente, de género, ideología, cultura y contingencia de los fenómenos revolucionarios, por contraposición al sesgo estructuralista de la tercera generación, centrada en exclusiva en el estudio del carácter «irracional» (y por eso mismo vulnerable) de los regímenes políticos que soportan procesos revolucionarios. Además, el mismo enfoque estructuralista se vio enriquecido al aplicarse a una multiplicidad de casos que no encajaban con el perfil de las revoluciones clásicas. En esta nueva andadura teórica es precisamente el proceso lo que importa más, con unos ingredientes básicos que siguen mucho más la orientación de Eisenstadt que la de Skocpol o Tilly: los procesos culturales e ideológicos de construcción de identidades, la identificación de las masas con las ideologías revolucionarias, la formación de redes, el liderazgo y el estudio de las élites dirigentes. Además, la definición del fenómeno se vio ampliada para recoger situaciones de «política conflictiva» relacionadas con la presencia de movimientos sociales que tienden a producir cambios permanentes en la distribución del poder dentro de la sociedad y que in-

45 Véase Charles Tilly (1979).

46 Véanse Patrick Baert y Bryan Turner (2004) y Thora Margareta Bertilsson (2004). 
vierten el enfoque tradicional, haciendo que lo problemático no sea ya el conflicto, sino la estabilidad social y las condiciones de mantenimiento de los regímenes y de sus políticas, en función de su capacidad de adaptación —algo que ya había sido explorado por Gurr y Eckstein a mediados de los setenta—47, en un contexto mucho más complejo que el tradicional, en el que, en lugar del antagonismo clásico entre las élites dirigente y pretendiente, aparecen cada vez con más frecuencia juegos de equilibrio entre múltiples actores. En el debate sociológico, la contraposición entre estructura y agencia se convierte en la dicotomía contingencia/inherencia. Para esta última, los conflictos latentes de bajo nivel resultan cruciales para explicar el desencadenamiento de las guerras civiles, cuya dinámica requiere echar mano de la interacción entre ambas vertientes analíticas ${ }^{48}$.

Esta nueva vertiente no admite una síntesis tan esquemática —ni un protagonismo personal tan destacado - como los de anteriores generaciones porque — una vez abandonada la preocupación por las grandes revoluciones de la modernidad - la riqueza, heterogeneidad y complejidad de los diferentes procesos revolucionarios de la segunda mitad del siglo xx —las múltiples revoluciones comunistas, anticomunistas, tercermundistas, nacionalistas e islamistas- se avienen mal con el recurso fácil a la abstracción y a la simplificación reduccionista. Además, el estudio se ve impulsado actualmente no sólo por las preocupaciones académicas e intelectuales, sino por la necesidad de contar con instrumentos para el análisis y la acción política. De ahí que la propia definición de revolución haya tenido que ensancharse, para incluir en ella los colapsos revolucionarios de regímenes totalitarios seguidos de transiciones democráticas escasamente violentas. Por no hablar de los frecuentes nexos entre el estudio de las revoluciones y el de los movimientos sociales — dinámica en la que destaca la participación de Tilly-, y una preocupación mucho más rica por los resultados revolucionarios. La definición de revolución proporcionada por Goldstone es bien significativa al respecto:

«La revolución es un esfuerzo por transformar las instituciones políticas y las justificaciones de la autoridad política en una sociedad, acompañado de movilizaciones

\footnotetext{
47 Véanse Gurr (1974) y Eckstein y Gurr (1975). El estudio de Gurr estableció que los sistemas políticos complejos —resultado del proceso de diferenciación en las pautas de ejercer la autoridad política bajo regímenes de poder mixto o dividido- sólo habían resultado más duraderos y estables en Europa — dentro de una muestra de países y políticas que excluía a los Estados formados tras la Segunda Guerra Mundial y abarcaba el período comprendido entre 1800 y 1971 - Gurr lo atribuía a que tal pauta de estructuración del sistema político resultaba «coherente» con el proceso de diferenciación en otros subsistemas sociales, fruto del proceso de modernización. Al igual que sucede con la denominada «convergencia condicional» entre países con instituciones homogéneas, observada en los procesos de desarrollo económico, se verificaba aquí también la hipótesis de «congruencia o consonancia» entre sistemas, formulada por Eckstein, según la cual las instituciones políticas funcionan mejor y duran más si sus pautas de autoridad resultan congruentes con las de los sistemas e instituciones sociales adyacentes, y si son internamente consonantes. Sin embargo, la «dimensión civilizatoria», introducida por Eisenstadt (2000) en el análisis sociológico, hace énfasis precisamente en el carácter problemático de esa congruencia, que constituía el presupuesto de los enfoques evolucionista clásico, marxista y estructural-funcionalista. Recientemente, Colomer (2001) ha constatado empíricamente la generalización de la tesis de mayor eficiencia de los sistemas políticos complejos con poder dividido.
}

48 Véase Lichbach et alia (2004). 
- formales o informales - de masas y de acciones no institucionales que debilitan a las autoridades existentes ${ }^{49}$.

Lo más sobresaliente de esta nueva definición es la desaparición de la más mínima referencia a la orientación de la acción, a la finalidad perseguida, al tipo de proyecto — si es que existe-; esto es, al contenido de la transformación pretendida por la revolución. En parte, esto es consecuencia del olvido de la divisoria señalada por Eisenstadt. Si las revoluciones inglesa e iraní han de caber en el mismo concepto, tal cosa resulta inevitable. En ambos casos los principales participantes afirmaron seguir orientaciones trascendentes, pero mientras los puritanos de Cromwell implantaron un orden mundano —que otorgó el poder al Parlamento-, los Chiís de Jomeini implantaron la república islámica, que otorgó el poder a los Ayatollahs para gobernar mediante edictos islámicos (Fatwah) y poner en marcha tribunales penales religiosos. Podría, pues, afirmarse igualmente que se trata de cosas distintas, separadas por la convicción luterana de que el orden divino no es cognoscible por el hombre - por mucho que la república calvinista de Ginebra hubiera incurrido en un primer contrasentido en tiempos de Calvino, que las guerras de religión de los siglos XVI y XVII contribuyeron a depurar.

En realidad, ingredientes profundamente irracionales — revestidos casi siempre de trascendentalismo - no han faltado en casi ninguna revolución. Barrington Moore ${ }^{50}$ ha estudiado, precisamente, el papel que desempeñó la exigencia de pureza moral en la delimitación nítida de fronteras entre participantes y perseguidos en la guerra civil religiosa de Francia en el siglo XVı —que no llegó a convertirse en revolución «gracias» al baño de sangre de la noche de San Bartolomé de 1572-. La secularización del concepto de pureza moral realizada por los revolucionarios Jacobinos dos siglos más tarde no le hizo perder eficacia persecutoria o sanguinaria, y, a partir de entonces, el concepto de pureza revolucionaria -revestido de cualquier ropaje doctrinal: nacional, secular o religioso- ha dado idéntico juego a la hora de exterminar opositores y disidentes por el nazismo, el estalinismo, el maoísmo de la revolución cultural, el khemerismo, el fundamentalismo hindú, o en las operaciones de limpieza étnica de Rwanda o la antigua Yugoslavia. Es más, parece que la secularización ha hecho de la pureza un instrumento de criba todavía más brutal, dando a las operaciones de exterminio un carácter menos litúrgico y más industrial, porque la burocratización y racionalización que suelen acompañarla proporcionan un instrumento más eficiente de cumplimiento de fines ${ }^{51}$.

\footnotetext{
49 Jack A. Goldstone (2001). Significativamente, las 48 páginas del estudio de esta generación contrastan con las 28 dedicadas en 1980 al de las tres generaciones precedentes.

50 Barrington Moore, Jr. (2000).

51 Barrington Moore, Jr. (1955).
} 
Mención aparte merecen las denominadas «revoluciones de terciopelo», que - dependiendo del concepto de revolución que se maneje - pueden contemplarse alternativamente como nuevas revoluciones o como acto final de la revolución soviética, una vez agotados sus efectos y extinguidas biológicamente las élites que ocuparon el poder a partir de 1917, paulatinamente gerontocráticas, tras un largo periplo de más de ochenta años en el que la promesa revolucionaria de una mayor felicidad colectiva derivada del nuevo modo de articular la organización social se demostró radicalmente infundada — por comparación con la modalidad de organización alternativa, la democracia, implantada en aquella misma fecha, que resultó evolutivamente seleccionada, por mejor «adaptada»-, lo que hasta las mismas élites dirigentes post-revolucionarias estaban ya dispuestas a admitir — de modo que su circulación dejó de producir lealtad ${ }^{52}$ - , por lo que ni siquiera ofrecieron resistencia y las masas defraudadas, privadas de voz, sólo tuvieron que esgrimir la amenaza de salida ${ }^{53}$ para cambiar el régimen.

Algo similar ocurrirá inevitablemente con la mayor parte de las revoluciones comunistas, ya se trate de la china, la cubana, la vietnamita, etc., en procesos que se verán facilitados, sin duda, por el avance en el acervo de conocimiento económico e institucional registrado con motivo de la verificación de los dos modelos alternativos de política económica diseñados para orientar la transición de las economías - y las sociedades - de Estado centralizadas hacia la economía de mercado, ambos de inspiración neoclásica: el modelo gradualista-incrementalista y la terapia de choque, diferenciados no sólo por la escala de tiempo y la velocidad prevista para el proceso de cambio, sino por la mayor o menor capacidad de uno y otro para tomar en consideración los factores institucionales, los procesos de aprendizaje y las restricciones impuestas por las condiciones iniciales - por completo diferentes a las vigentes en las economías industriales avanzadas, que el modelo neoclásico presupone-. La diversidad de estas experiencias ha permitido acumular una masa considerable de evidencia empírica y evaluar ex post facto el comportamiento de los agentes implicados y de las políticas aplicadas. De ahí que, con independencia de sus consecuencias societales, el proceso de transición haya sido considerado como el mejor observatorio científico para la contrastación de las teorías al uso, no sólo en el ámbito de la economía, sino en múltiples campos de las ciencias sociales, y especialmente en el de la ciencia política, ya que en tales circunstancias «la política no es un factor externo para la economía, sino una variable endógena que impone múltiples restricciones $\$ 54$.

\footnotetext{
52 Véase Valery Lazarev (2002).

53 Véase Albert O. Hirschman (1993).

54 Véase Marangos (2005).
} 
Puede aducirse que al contemplar el proceso revolucionario a lo largo de un período tan dilatado de tiempo (1917-1989/91) quiebra la percepción intuitiva de que la revolución es, por definición, un proceso de ocurrencia relativamente breve. Pero esa percepción queda igualmente rota cuando se habla de la revolución inglesa —o, más bien, del «ciclo revolucionario inglés»- del siglo XVII, que, dependiendo del enfoque adoptado, puede circunscribirse al período 1640-1660 o abarcar el proceso completo comprendido entre la Petición de Derechos de 1628 y la Declaración de Derechos de 1689, con el acceso al trono de Guillermo y María, príncipes de Orange. Y, con un carácter algo más laxo, igual sucede con la Revolución francesa, cuya salida definitiva no se alcanzaría hasta el final del segundo imperio, con el establecimiento de la Tercera República en 1871 - o, como mínimo, hasta la Segunda República, de 1848- ya que las sucesivas etapas previas pueden contemplarse como resultado de movimientos de acción-reacción derivados de la Revolución de 1789, como bien observó Carlos Marx. Por extensión, el ciclo revolucionario español del XIX tampoco puede darse por cerrado hasta después de la «Revolución» de $1868^{55}$.

Desde la perspectiva abierta por Eisenstadt, esas dos grandes cosechas de revoluciones o ciclos revolucionarios responden a dos proyectos alternativos y sucesivos de modernidad: los de las revoluciones liberal —continuada en la democracia- y socialista. En principio, los modelos teóricos de una y otra contaban con probabilidades de éxito igualmente inciertas. Es más, dentro del modelo liberal, la perspectiva ilustrada centroeuropea consideró siempre que la astucia de la razón de la mano invisible, ideada por Adam Smith ${ }^{56}$, resultaría menos consistente como maqueta de progreso que el modelo de desarrollo patrocinado por Saint-Simon en Francia o por Federico Liszt y los socialistas de cátedra en Alemania, fuertemente tutelados ambos por el nuevo Estado liberal.

Todavía a mediados del siglo xIx, Carlos Marx concluía, cargado de evidencia empírica, que el modelo de la economía política clásica condenaría al proletariado a la esclavitud sempiterna, lo que suscitó temor creciente en las filas obreras de todo el continente. Sin embargo, la evolución subsiguiente, hasta la Primera Guerra Mundial, demostraría que su vaticinio estaba equivocado, porque los salarios reales ingleses se duplicaron. Pero esto no apagó la sed revolucionaria. La deprivación causada por la Gran guerra dio paso a la revolución bolchevique, que Schumpeter contempló descarnadamente como un «exquisito experimento de laboratorio ${ }^{57}$, paralelo a la universalización del sufragio en el resto de Europa.

\footnotetext{
55 Véase Miguel Artola (1973).

56 Véase A. Espina (2005a).

57 Lo que le valió una reprimenda pública de Max Weber. Véase Richard Swedberg (1991).
} 
Pero el experimento no dio resultado y, aunque duró casi un siglo, a la larga hubo que sustituirlo por el modelo alternativo. De ahí la respuesta del Primer Ministro chino, Chou En-lai, cuando se le preguntó acerca de la influencia de la Revolución francesa en el mundo, al responder: «todavía es pronto para extraer conclusiones», intuyendo que su repercusión sobre China todavía estaba por llegar. Mikhail Gorbachev utilizó esa anécdota para ilustrar el hecho de que el siglo xx hubiera sido para Rusia un siglo de búsqueda de su propio modelo de sociedad, tras el cual la Perestroika se impuso sin graves dificultades, aunque con dolor colectivo y amplios daños sociales. La hora de sacar conclusiones y de pasar a la democracia había llegado ${ }^{58}$. A ello se añadía la decepción cognitiva que venía experimentando el mundo comunista desde mucho tiempo antes, cuando empezó a quedar claro que la convergencia histórica hacia esa forma de organización social — que constituía su prueba de veracidad legitimadora, al haber sido presentada ex ante como científicamente inevitable por Marx y los fundadores- se había demostrado intelectualmente infundada ${ }^{59}$.

La clave de todo ello se encuentra en la explicación evolucionista. Una vez depurada una «variedad» de organización social que demuestra ser la más adaptada o eficiente, ésta tiende a constituirse en polo de atracción, imitación y contagio. El sistema democrático, libre de corrupción o captura plutocrática y capaz de garantizar el Estado de Derecho, se configura paulatinamente a lo largo de los siglos XIX y XX no como fin de la historia, sino -en palabras de Eisenstadt- como comienzo o hecho fundacional de una nueva civilización y ésta, a su vez, en precondición para el desarrollo económico y el bienestar de la población. La voluntad de ruptura con el pasado axial —aunque recuperando su impulso, a través del concepto trascendente del derecho natural- y los elementos germinales de la nueva forma organizativa aparecieron por primera vez en los Países Bajos en el siglo XVI -que se inspiraron en los ensayos veneciano y florentino del siglo anterior-; en el siglo XVII se exportaron a Inglaterra — al tiempo que Holanda se libraba de la amenaza española-, para pasar a Norteamérica en el $\mathrm{XVIII}^{60}$, de donde enseguida volverían a Francia, convertidos ya en verdadero motor que impulsa a la astucia de la razón ilustrada. Bonaparte trataría de imponerlos por la fuerza a lo largo y ancho del continente europeo a comienzos del siglo XIX, de donde se exportaron a Sudamérica y al resto de colonias y dependencias europeas en el transcurso del siglo subsiguiente.

En realidad, en lugar de una serie de revoluciones separadas, de lo que estamos hablando es de la expansión y diseminación de la nueva civilización definida por Eisenstadt. Puede

\footnotetext{
58 Véase Mikhail Gorbachev (2002).

59 Véase Giuseppe di Palma (1991).

60 El análisis clásico del proceso de selección es el de Graham Sumner (1911). Véase mi comentario sobre su obra en este mismo número de REIS. Mi análisis del caso histórico europeo, en Espina (2001a).
} 
decirse que el asunto llega hasta nuestros días. La caída de los regímenes comunistas y su sustitución por el modelo de democracia liberal $-\mathrm{y}$ movimientos convergentes desde regímenes autoritarios y/o corruptos de signo contrapuesto- constituyen otros tantos pasos de este proceso, que lo consolida como la única opción viable y le hace alcanzar una dimensión prácticamente global, con sólo algunas excepciones. La revolución iraní y la serie de nuevos ensayos fundamentalistas que le siguieron no parecen capaces de perdurar, porque la inseguridad jurídica y la subordinación del individuo, inherentes a las teocracias, son otros tantos obstáculos insuperables para la creación de riqueza, el desarrollo económico y el despliegue de la iniciativa individual. Y, en ausencia de estos últimos, ninguna mística identitaria ha sido nunca capaz de mantener cohesionada a la población durante largos períodos de tiempo.

Lo que no quiere decir que su colapso esté garantizado a corto plazo. Sucederá más bien como ocurrió en el Este de Europa, en donde el derrumbe era previsible e inevitable, pero no por ello dejó de ser inesperado, ya que la estructura del régimen había convertido en inobservables los signos de su propio desgaste y de la acumulación de antagonismo encubierto que condujo a su gestación. Algo que, según Tocqueville, había ocurrido también antes de la Revolución francesa, en la que la acumulación de disidencia habría durado seis generaciones -e igual sorpresa produjeron en su momento las revoluciones soviética o iraní-. Lo que sucede es que el conjunto de factores que conduce a la revolución no está relacionado entre sí linealmente, de modo que pequeñas perturbaciones en alguna de las variables — cuando el efecto de causación acumulativa ya ha tenido lugar- son susceptibles de desencadenar efectos desproporcionadamente grandes en otras variables, como sucede en el modelo de cambios climáticos de Edward Lorenz, o en los modelos de rendimientos crecientes de Brian Arthur ${ }^{61}$.

Todo ello no implica que la explosión revolucionaria responda a factores irracionales; antes al contrario. A veces, lo que resulta difícil de explicar es la estabilidad y la acomodación de la sociedad civil a situaciones de «deprivación» aguda. Sencillamente, su racionalidad no puede ser explicada por causación lineal simple y continua, sino por causación probabilística compleja y discontinua, lo que otorga al fenómeno revolucionario su carácter explosivo. E igual sucede en muchos otros episodios de cambio brusco de orientación colectiva, en los que previamente existe «falsificación de preferencias» u «ocultación de voto», porque la sociedad ejerce alguna forma de censura informativa que produce «inobservabilidad imperfecta».

61 Véanse Timur Kuran (1991) y Arthur (1996). 
Obviamente, esto es mucho más frecuente en regímenes totalitarios y autoritarios —en los que el propio individuo tiende a ejercer una férrea autocensura cognitiva ${ }^{62}$, pero aparece también en muchos contextos democráticos ${ }^{63}$, especialmente cuando los «obstáculos técnicos» hacen que el derecho a la participación electoral se vea intermediado por los procedimientos de inscripción, que son siempre selectivos en función de variables tales como el nivel educativo, el grupo cultural de pertenencia, el nivel de ingresos, el tipo de hábitat, etc. Podría afirmarse, incluso, que la carencia de censos electorales automáticos confeccionados directamente y permanentemente actualizados por parte de los poderes públicos se comporta en la actualidad como un filtro selectivo similar a los empleados por los regímenes de liberalismo censitario durante el siglo XIX, lo que explica la escasa participación política en tales sistemas, a los que cabría denominar «democracias censitarias» 64 .

Sin embargo, la doctrina del «choque de civilizaciones», de Huntington ${ }^{65}$, apela directamente a la irracionalidad y se sitúa en las antípodas del proceso de universalización que ha discurrido históricamente a través de la apertura progresiva de las culturas particulares y de la adopción voluntaria del modelo a través de la acción colectiva. Porque si la palabra revolución dispone de alguna acepción unívoca, ésta exige que las masas asuman por sí mismas la responsabilidad sobre su propio destino. La tesis del choque, en cambio, no soporta la prueba de la contrastación empírica a la hora de explicar los conflictos internacionales reales registrados en nuestro tiempo ${ }^{66}$, pero eso no le ha hecho perder eficacia, al inspirar el programa neoconservador del Presidente G. W. Bush, por el que EE.UU. asume unilateralmente la misión de extender el credo occidental como nuevo orden global —algo a lo que sólo se puede denominar «revolución» neoconservadora violentando la extensión analógica del concepto.

62 En el film «El Hundimiento» (2004), de Olivier Hirschbiegel, la propia secretaria de Hitler, que transmite las instrucciones del Führer a sus colaboradores, alega desconocimiento acerca de lo que ocurría bajo el nazismo.

63 Véase Timur Kuran (1991).

64 Paradójicamente, en EE.UU. la resistencia a la inscripción censal automática goza de tal tradición —similar a la adopción de un sistema nacional de identificación-que el problema apenas se menciona entre los obstáculos al voto recogidos por el IPS Election Monitoring Team tras las últimas elecciones (Dolan y Sugget, 2004).

65 El choque fue anunciado hace más de una década por Samuel Huntington (1993 y 1996), que enfatiza el carácter único, no universal, de la civilización occidental (pp. 71 y ss. y 311 y ss.), y se inscribe no en la tradición evolucionista, sino en la del mecanicismo sociobiológico, en donde la lucha por la supervivencia es sinónimo de guerra. Recientemente, Huntington decidió llevar el choque al interior mismo de los EE.UU., otorgando a los WASP la condición de fuerza identitaria y salvadora de la civilización. Véase Peter Carlson (2004). Mientras, su idea originaria es adoptada como leit-motiv del enfrentamento entre derecha e izquierda en España: véase «Aznar defenderá los valores occidentales frente a "la alianza de civilizaciones" , $A B C$, 14-III-2005.

66 Véase Errol A. Henderson (2004). 
El Presidente George W. Bush adoptó durante su primer mandato esta tradición como ideal de cruzada que no admite la menor equivalencia moral — porque piensa que el american way of life es el único moralmente decente y racionalmente defendible, lo que legitimaría su imposición por la fuerza - La denominación «Operación Libertad para Irak», inscrita sobre las bombas lanzadas sobre ese país, resulta orwelliana, según el antropólogo Richard A. Shewer ${ }^{67}$. Sin embargo, ha contado y cuenta con apoyos liberales ardientes, que son señal del profundo arraigo de que todavía disfruta la convicción según la cual Occidente tiene la atribución «de promulgar pautas morales objetivas y universalmente vinculantes» y de extenderlas a través de su acción misionera y belicosa. Éste no es, obviamente, el camino a seguir. Lo que no significa dudar acerca del progreso moral, sino rechazar la utilización abusiva de esa idea - en tanto el fundamentalismo no constituya una amenaza directa, como sucedió en Afganistán-. El rechazo de la vía de imposición es resultado, más bien, del firme convencimiento de que la civilización abierta acabará imponiéndose, sencillamente porque es la más beneficiosa para la humanidad, en términos comparativos, como se ha demostrado reiteradamente a lo largo del último medio milenio. Ésa es su «fuerza blanda», que puede fortalecerse mediante una estrategia global de cooperación cultural —como la «alianza de civilizaciones» propuesta por España y adoptada por el Secretario General de la ONU.

Volviendo al problema de la compresión revolucionaria del tiempo a la que se han tenido que enfrentar las élites dirigentes tradicionales cuando les llegó la hora del cambio, el hecho constatable es que la estrategia que consiguió evitar definitivamente las revoluciones a largo plazo apeló generalmente durante el siglo xx al tipo de reformas políticas que implicaban un cambio completo de «régimen», hasta llegar a la democracia. La economía política ha dirigido su atención estos últimos años al estudio de la interacción entre los procesos económicos y los institucionales ${ }^{68}$. Una de las preguntas planteadas ha sido: ¿qué es lo que indujo a ciertas élites occidentales, en lugar de practicar estrategias de ampliación paulatina del derecho de voto, a dar directamente el salto hacia su universalización?

A partir del caso de la revolución argentina de 1912, liderada inicialmente por Irigoyen y el Partido Radical, pero a la que se sumaron enseguida campesinos y trabajadores (anarquistas y socialistas), Acemoglu y Robinson aplican la teoría de juegos para construir un modelo de elección racional en el que juegan tres clases sociales (rica, media y pobre) y tres regímenes políticos: duro, flexible y débil. En caso de conflicto abierto, la concesión de derechos de sufragio a las clases medias tenderá a ser considerada por los pobres como un signo de debilidad y a acentuar, en lugar de atenuar, el grado de malestar, como sucedió

\footnotetext{
67 Véase Richard A. Shweder (2004) y, en general, todo el número de la revista, dedicado a revisar la idea de progreso, desde su formulación clásica por Condorcet. También, Mary Kaldor (2005).

68 Véase Graziella Bertocchi (2004).
} 
con la convocatoria de los Estados Generales por Luis XVI, que fue la causa que condujo a la Revolución, según Tocqueville. De modo que, en tales circunstancias, la clase rica se ve obligada a elegir entre la represión — con el riesgo de no disponer de fuerza suficiente y perderlo todo, dando paso a la revolución social—y la transición plena hacia la democracia.

El modelo funciona así: ante la situación de amenaza revolucionaria, la clase rica elige entre la represión, la concesión de derechos de voto a la clase media o la universalización de tal derecho (lo que depende del tipo de élite: dura, flexible o débil). Tras esta elección, la clase pobre actualiza la imagen que tiene de la clase rica y decide si debe desencadenar la revolución. En caso de hacerlo, la clase rica puede reprimirla utilizando medios costosos y destructivos: si pierde, la clase pobre expropia su capital; si gana, permanece en el poder.

En caso de que no haya revolución, el poder descansa sobre el votante mediano y la ubicación de clase de éste depende del sistema político. El tamaño de la clase pobre se supone superior a la mitad de la población, y el de la clase media superior al de la clase rica. Bajo tales supuestos, en las democracias restringidas (o regímenes liberales censitarios), en que los derechos de voto se limitan a las clases rica y media, el votante mediano pertenece a esta última. En cambio, la implantación de la democracia significa que el votante mediano se desplaza hasta la clase pobre — de ahí la relevancia de los filtros censitarios para caracterizar al régimen político: sólo los regímenes en los que no existen tales filtros disponen de Estados de bienestar avanzados.

La principal decisión sometida a votación consiste en el establecimiento de la presión fiscal. Por conveniencia analítica se supone que existe un tipo impositivo único y lineal, siendo distribuida la recaudación a partes iguales entre la población. Es el votante mediano quien dispone de la capacidad de decidir el proceso de redistribución de la renta -esto es: su intensidad y su escala temporal- El votante mediano decide en función de sus intereses, bajo la condición de exacción proporcional a la renta y de redistribución lineal entre la población. El examen de las distintas alternativas posibles indica que los principales resultados no cambian si se hace abstracción de las decisiones de la clase media.

El juego se somete a tres supuestos: a) la redistribución conseguida en condiciones de democracia perfecta — con Estado de bienestar- es más conveniente para la clase pobre que la que conseguiría en caso de victoria de la revolución; b) la represión de tipo flexible es más costosa que la redistribución parcial derivada de un régimen de democracia limitada o liberalismo censitario, en la que el votante mediano pertenece a la clase media; c) sin embargo, la estrategia de concesión de derechos de sufragio a la clase media, aunque mejore algo la redistribución para la clase pobre, no es suficiente para que esta última renuncie a la revolución — de ahí la inestabilidad de muchas «democracias censitarias». 
El análisis del juego en condiciones de equilibrio bayesiano con información perfecta (en que la clase pobre conoce perfectamente el tipo de élite a la que se enfrenta y calcula bien los resultados de cada decisión) indica que frente a la estrategia dura la clase pobre no hace la revolución porque pierde más de lo que gana. En caso de estrategia flexible, la élite, en lugar de reprimir, concede derechos de voto a la clase media y la clase pobre no va a la revolución porque sabe que la perdería. Finalmente, una élite débil no es capaz de reprimir la revolución ya que, aunque se hiciesen concesiones a la clase media, la clase pobre no detendría la revolución, así que triunfa la plena democratización.

En cambio, si la información de que se dispone no es perfecta, la estrategia dura es la única que despeja la incertidumbre sobre el curso de la acción de la clase rica, aunque resulte arriesgada. En este caso no ha lugar para una estrategia flexible de concesiones porque podría ser interpretada por la clase pobre como un signo de debilidad y obligar a adoptar sobre la marcha una estrategia represiva, con menores probabilidades de éxito. De modo que si bajo condiciones de información perfecta no había espacio para la revolución, con información imperfecta aparece la disyuntiva entre la estrategia dura, con riesgo de revolución, o la estrategia de plena democratización.

La probabilidad de que la clase rica adopte una estrategia dura y represiva aumenta allí donde la desigualdad social es extrema, porque en tal caso el coste de la democracia resulta mucho más elevado para los ricos - como sucedió históricamente en el modelo latino y puede suceder ahora con el desenlace final de algunas revoluciones independentistas criollas, prolongadas bajo regímenes de «democracia censitaria»- Todo ello concuerda básicamente con los análisis empíricos realizados por Ted Gurr y la segunda generación de teorías políticas de la revolución. Su formalización mediante la teoría de juegos facilita el razonamiento y una contrastación empírica mejor especificada.

En este modelo, el equilibrio sólo se alcanza en uno de los dos polos, haciendo buenas las palabras de Maquiavelo, según las cuales «los hombres sólo pueden ser mimados o aplastados» ${ }^{69}$. Este último fue el caso en muchos países latinos —empezando por España—, en los que las élites nunca estuvieron dispuestas a ceder poder político hasta que las masas o los grupos disidentes se alzaban y proclamaban declaraciones revolucionarias de derechos. Pero las revoluciones produjeron caos y dieron lugar a movimientos pendulares frecuentes - y a la interrupción cíclica del proceso de edificación del sistema social y económico一, siguiendo el modelo de "desarrollo antagonista" descrito por Hirschman ${ }^{70}$, cuya característica más sobresaliente consiste en la sangría periódica de los mejores recursos

69 Véase Daron Acemoglu y James A. Robinson (1999).

70 Véase Albert O. Hirschman (1992). 
humanos disponibles, consecuencia de la represión o el exilio, como siguió sucediendo en Sudamérica hasta los años ochenta del siglo pasado (siguiendo en esto el ejemplo de la «madre patria» durante el franquismo), fruto de la prolongación en el tiempo de regímenes profundamente inestables y frágiles, en los términos definidos por las teorías estructuralistas de la revolución. Y como la acumulación continuada de recursos humanos es condición necesaria para el desarrollo, este modelo impide el crecimiento autosostenido ${ }^{71}$, de modo que una vez los regímenes pierden vigor represivo, las masas imponen sin gran esfuerzo la vuelta al gran redil de la civilización occidental, cediendo al contagio evolucionista y exigiendo la implantación de la democracia.

En general, la evidencia indica que la salida final de los grandes conflictos sociales y políticos en los que aflora el antagonismo radical de intereses ha basculado entre la solución revolucionaria - con la consiguiente convulsión redistributiva inmediata y su disipación entrópica- o la transición rápida hacia la democracia. Ésta es contemplada por la población como una garantía de distribución de la renta a largo plazo, plasmada en el compromiso constitucional. El estudio de esta última forma de salida de los conflictos resulta especialmente relevante, no sólo de cara a impulsar la gobernabilidad del proceso de globalización, el bienestar y la equidad social, sino por cuanto la reducción de la desigualdad inherente a la modernización institucional y al avance de la democracia se ha demostrado imprescindible para el desarrollo económico a largo plazo. La modelización del proceso de extensión del derecho de sufragio llevada a cabo por Acemoglu y Robinson — que imputa la determinación final del mismo a la amenaza latente de revolución - resulta más consistente con los hechos históricos que explicaciones alternativas que basan simplemente el movimiento de extensión en el cambio de valores culturales producido por la llustración, en la competencia por el voto entre partidos tradicionales o en el simple aumento de peso de la clase media. Eso es lo que da al modelo un aroma fuertemente evolucionista.

La evidencia de que en el largo plazo la única solución estable es la democrática no terminó de imponerse hasta finales del siglo xx, que es cuando las revoluciones socialistas llevadas a cabo en el transcurso del siglo acabaron de consumir su energía y no encontraron otra salida viable. Esto ya había sido anticipado cuando, tratando de evitar la revolución durante el primer tercio del siglo xx, las élites europeas comprendieron que el compromiso redistributivo que les era arrancado con violencia durante la fase de agitación pre-revolucionaria no hubiera resultado creíble para las masas sin ampliar los derechos de voto, hasta generalizarlos, lo que llevaba implícito redistribuir a lo largo del tiempo, diluyéndolos, los efectos de la presión conflictiva inicial. De ahí que en Europa la fecha de la universalización del derecho de sufragio coincidiera generalmente con el momento en que la curva de Kuz-

71 Véase Oded Galor y Omer Moav (2003). 
nets de distribución de la renta alcanzó su punto de máxima desigualdad, para empezar a reducirse a partir de entonces, lo que implica escalas de tiempo divergentes para las clases rica y pobre, aproximadas, sin embargo, mediante el Estado de bienestar ${ }^{72}$. En cambio, las «democracias censitarias» tienen todavía pendiente este último paso.

\section{REVOLUCIÓNY TEORÍA DE LA CIRCULACIÓN DE LAS ÉLITES: UN MODELO ANALÍTICO}

Una estrategia alternativa a la revolucionaria y al brusco salto democrático la enunció Pareto en su «teoría de la circulación de las élites». En el contexto de la denominada primera generación de teorías de la revolución, Crane Brinton señaló que suelen ser precisamente las minorías ilustradas de las clases sociales en ascenso (las inteligentsias) las que perciben con mayor claridad y de forma más lacerante que la situación preexistente cercena su potencial de desarrollo, por lo que la formulación explícita y la manifestación abierta de sus quejas constituyen frecuentemente el primer síntoma revolucionario ${ }^{73}$. Cuando esto sucede, la compresión del tiempo que caracteriza a las situaciones revolucionarias dificulta en extremo su asimilación por las oligarquías tradicionales, por lo que las concesiones parciales de derechos aparecen como signo de su debilidad, mientras que en una escala de tiempo diferente podrían haber dado paso a un proceso evolutivo. La anticipación reflexiva resulta aquí el hecho determinante —como sucedió en el caso de Inglaterra durante el siglo XIX, que desactivó la confrontación radical mediante la reforma parlamentaria de 1832 , seguida de extensiones paulatinas del derecho de sufragio, que no se haría universal para los mayores de 21 años hasta 1928.

Pareto observó que las sociedades en las que la pertenencia a la élite dirigente no es hereditaria, sino adscriptiva, y su renovación se realiza a través de la movilidad ascendente de los individuos más esclarecidos de las clases subordinadas, la cooptación de estos individuos incorpora también parte de sus ideas, facilita la asimilación progresiva de nuevas «variedades» —utilizando el leguaje evolucionista de Walter Bagehot, para quien la innovación social equivale analógicamente, como vimos, a las mutaciones en el proceso de selección de las especies - e impulsa la evolución institucional, reduciendo la acumulación de descontento y la manifestación de disidencia que, en ausencia de "circulación de las élites», conducirían a la revolución ${ }^{74}$.

\footnotetext{
72 Véase Daron Acemoglu y James A. Robinson (2000).

73 Véase Crane Brinton (1965).

74 Véase Vilfredo Pareto (1935). Una selección de vols. III y IV (Secciones 2026-2029 \& Ss. 2233-2236) puede verse en http://www2.pfeiffer.edu/ /ridener/courses/CIRCELIT.HTML (19-6-2005).
} 
Las técnicas de optimización y programación matemática han permitido recientemente modelizar esta política, estilizando sus supuestos y proyectándolos sobre un plano estrictamente materialista, aunque las motivaciones y el conjunto de escenarios estudiados no sean exclusivamente económicos, lo que facilita la explicación de la alternativa cooptación/ revolución en términos de la teoría de la elección racional ${ }^{75}$. El modelo simula matemáticamente la cooptación de los elementos más activos de la clase dominada (grupo dos) por la dominante (grupo uno) para formar una nueva clase (grupo $C$ ), intermedia entre las dos clases sociales enfrentadas. Utilizando las facultades redistributivas coactivas de que dispone, el grupo uno ofrece al grupo $C$ un nivel de participación en el statu quo suficiente para compensarle por dejar de apoyar la insurgencia de su clase de origen -y los beneficios de todo tipo que obtendría en caso de revolución victoriosa-. La probabilidad revolucionaria (PR) se hace depender de la proporción que representa el grupo dos residual respecto a la población total, elevada a un parámetro determinado por su fuerza y capacidad organizativas, parámetro que disminuye a medida que aumenta la tecnología revolucionaria y se supone inferior a uno, de modo que sus variaciones producen un efecto exponencial y su aumento equivale a una disminución de la PR.

La revolución ocurre cuando la magnitud resultante — su probabilidad de ocurrencia- es superior a la fracción representada por la suma de los grupos uno y $C$. En caso de revolución, estos dos grupos lo pierden todo, mientras que el resto del grupo dos se reparte la riqueza residual, tanto mayor cuanto mejor y menos destructiva es la tecnología revolucionaria. El bien ofrecido a cada miembro del grupo cooptado ha de ser, lógicamente, superior a las expectativas de ingresos derivados del reparto de la riqueza no destruida en el proceso revolucionario entre los miembros del grupo dos residual —en el que se encontrarían los miembros de $C$, de no haber aceptado la cooptación-, ponderadas ambas magnitudes por la probabilidad de que fracase o triunfe la revolución, respectivamente (probabilidades que son, obviamente, complementarias).

Los tamaños del grupo $C$ y del grupo dos residual son determinados por el modelo de forma endógena utilizando la técnica de programación lineal para maximizar la función objetivo del grupo uno. Ésta consiste en minimizar el coste total de la cooptación, lo que implica que tanto el tamaño del grupo $C$ como la oferta de cooptación hecha a cada uno de sus miembros deben tener la dimensión mínima imprescindible. Bajo este conjunto de restricciones, si todos los agentes actúan racionalmente, el modelo determina que cuanto más destructiva sea la revolución y/o cuanto menos eficiente la tecnología revolucionaria (y la capacidad organizativa), mayor deberá ser el tamaño del grupo cooptado (C) pero menor la cantidad ofrecida a cada uno. Esto se debe a que mayores expectativas de destrucción de

\footnotetext{
75 Véase Graziella Bertocchi y Michael Sapagat (2001).
} 
riqueza equivalen a menores expectativas de reparto del botín revolucionario, lo que reduce el incentivo a participar en la revolución de quienes permanecen en el grupo dos.

Además, una tecnología revolucionaria menos eficiente disminuye también la probabilidad de revolución y estimula al grupo uno a cooptar a más gente del grupo dos a menor coste (porque estos últimos consideran menos probable llegar al reparto revolucionario). En cambio, cuanto menor sea la proporción del grupo dos inicial, menor deberá ser también la del grupo cooptado (porque también es mayor la del grupo uno), pero más elevado podrá ser el precio ofrecido por cada cooptación (porque el coste se reparte entre un número mayor). En cualquier caso, el tamaño del grupo cooptado no depende del nivel ni de la distribución inicial de la renta, sino del status relativo de los tres grupos después de llevar a cabo la cooptación. En conjunto, cuanto mayor es el grupo uno, menor es el coste total de la redistribución.

Esto es lo que ocurre cuando los individuos del grupo dos son considerados por separado de manera atomística y las decisiones de unos no influyen sobre las de los otros, lo que permite a la élite dirigente emplear la estrategia «divide y vencerás», y aconseja al analista mantener el más estricto individualismo metodológico. Pero en otros casos —particularmente cuando el grupo dirigente es muy reducido, autoritario y opulento, y las condiciones de vida del grupo mayoritario muy precarias y homogéneas - las decisiones de aceptar o rechazar la oferta de cooptación se adoptan en grupo (en palabras de Marx, la clase en sí es también clase para sí ). En estas circunstancias, la combinación de una buena tecnología revolucionaria (con plena unidad de clase, lo que implica buena organización) y una escasa probabilidad de destrucción conduce a que no exista cooptación (porque resulta demasiado caro cooptar a todo el grupo dos), a que el grupo uno se bunkerice y a que estalle la revolución, mientras que en caso contrario (con escasa tecnología y grave riesgo de destrucción a través de la guerra civil) existe plena cooptación, lo que conduce a la democracia, como sucedía en el modelo de Acemoglu y Robinson.

Existe también un escenario con fragmentación intermedia, en el que el grupo dos resulta heterogéneo y puede segmentarse en varios subgrupos (étnicos, religiosos, profesionales, en razón de su renta, etc.), con suficiente confianza en su interior —cualquiera que sea el fundamento de ésta- como para coordinar sus decisiones, pero con escasa solidaridad intergrupal. Este escenario se corresponde en parte con la «segunda generación» de teorías sociológicas de la revolución, que se ha visto revitalizado al término de la guerra fría por la eclosión de un gran número de conflictos — denominados despectivamente «conflictos tribales»- en los más virulentos de los cuales el hecho distintivo no consiste en el intento de secesión, sino en la disputa por el poder estatal entre grupos étnicos o con características de afinidad no estrictamente económicas en el seno de Estados de formación reciente. 
Tales conflictos vienen produciéndose desde el final de la Segunda Guerra Mundial, pero su frecuencia aumentó al término de la guerra fría, afectando, principalmente en África, a países pobres con Estados débiles y poblaciones étnicamente heterogéneas, lo que plantea con especial agudeza el problema de la intervención humanitaria internacional. Por mucho que la lucha por el poder en este tipo de conflictos implique disputas por la distribución de la riqueza, el aspecto material no es el predominante en ellos, sino más bien los de hegemonía étnica y democratización de regímenes dictatoriales, de modo que el supuesto de actores racionales frecuentemente no se sostiene. El propio Ted Gurr sintetizó en 1994 el estudio de 125 conflictos etnopolíticos ocurridos desde 1945 con frecuencia creciente, en los que participaron 233 grupos étnicos diferentes ${ }^{76}$.

Por contraposición al modelo de segunda generación de Gurr, el de Bertocchi y Spagat hace abstracción de la existencia de frustración de expectativas entre los diferentes grupos - si bien es cierto que la presupone, o se anticipa a su aparición-o de las ambiciones de hegemonía, analizando este tipo de dinámicas en términos de actitudes y preferencias reveladas, como corresponde a la orientación general de las ciencias económicas (mainstream economics), lo que les impide captar el núcleo esencial de algunos de estos conflictos - precisamente los más violentos-, en los que las motivaciones de clase social no son las más determinantes. Por razón de conveniencia analítica se supone, además, que la segmentación produce grupos de tamaño similar y que la proporción de cooptados es igual dentro de cada uno de los subgrupos - lo que resulta óptimo para el grupo uno, en orden a mantener a la clase cooptada lo más dividida posible-. Bajo tales circunstancias, las soluciones al problema de minimización del coste económico no son cerradas, aunque tienden a moverse en la misma dirección que en el caso de plena fragmentación.

Ahora bien, el grupo $C$ cooptado puede no ser completamente homogéneo respecto al grupo dos de origen. Puede tratarse de un grupo de élite, «una clase media emergente», cuyos objetivos no son necesariamente expropiatorios — como se supone que lo son los del grupo dos residual, que se encamina hacia la revolución de orientación socialista, presente en toda revolución, desde la inglesa del siglo xvII, representado por los levellers y los diggers $^{77}$ - , sino que persiguen incrementar su riqueza al mismo tiempo que su poder $-\mathrm{y}$ a veces lo uno no puede lograrse sin lo otro-, mientras que la cooptación que les ofrece el grupo uno no los integra plenamente en él, que conserva íntegra su capacidad dirigente. Para analizar cuantitativamente esta situación, Bertocchi y Spagat simulan un segundo tipo de revolución en la que, caso de resultar victoriosa, el grupo uno y el grupo $C$ cooptado se reparten equitativamente toda la riqueza y expropian completamente al grupo dos residual.

\footnotetext{
76 Véase Ted Robert Gurr (1994).

77 Sobre el principal dirigente de los diggers puede verse Christopher Hill (1996).
} 
Esta simplificación economicista es resultado en realidad de la integración del grupo $C$ en el grupo uno para compartir las facultades de decidir el sistema de distribución de la riqueza en la sociedad, lo que implica una considerable «apertura» recíproca de los dos grupos. Tal revolución puede materializarse bajo la forma de avances en la extensión de los derechos de voto, como los que se produjeron en el siglo XIX, tras la «revolución liberal», dando lugar a las diferentes fórmulas de liberalismo censitario, empezando por la reforma parlamentaria inglesa de 1832. En cambio, su utilidad para el estudio de los conflictos etnopolíticos —o para los puramente axiales, de tipo fundamentalista— parece más limitada.

Se supone que la revolución liberal — de tipo 2- aparece como alternativa a la revolución de masas - de tipo 1, expropiatoria-, pero en aquel caso el grupo revolucionario es $C$, y la probabilidad de que ocurra será tanto mayor cuanto más elevada sea la fracción que representa $C$ en el conjunto de la sociedad (elevada a un coeficiente, inferior a uno, tanto más bajo cuanto mejor sea la tecnología revolucionaria de tipo liberal), acumulada por producto a la probabilidad de que no ocurra la revolución de masas (complementaria de su probabilidad de ocurrencia). En este caso el precio que el grupo uno está dispuesto a pagar a cada individuo cooptado es más reducido, porque la élite cooptada sólo renuncia a la revolución de masas, pero no a la liberal. Este menor coste facilitaría que el grupo uno aumentase el número de cooptados, pero aumentar la cooptación plantearía nuevos problemas al grupo uno porque elevaría el riesgo de revolución liberal, lo que le aconseja más bien reducir el tamaño de $C$. Una vez resuelto el problema de maximización, el resultado es que esos dos efectos se neutralizan y el número de cooptados sigue siendo el mismo que en el caso en que se afrontaba la amenaza de una sola revolución. Sin embargo, la amenaza latente de revolución liberal hace que el volumen total de transferencias para neutralizar la amenaza de la revolución de masas sea más reducido, lo que se ve compensado por el hecho de que la élite cooptada conserva su expectativa de participar en su propia revolución (de carácter liberal). Finalmente, esta última no tiene por qué suponer una amenaza tan temible para el grupo uno como la revolución de masas, ya que el grupo $C$ puede ofrecer la posibilidad de integrarse en la nueva élite a todo el grupo uno o a parte de él, como sucedió en la España del siglo XIX ${ }^{78}$.

La probabilidad de que se produzca una revolución de masas no depende sólo del tamaño relativo de los grupos uno y dos, sino también del nivel de la renta. La evidencia empírica de lo ocurrido en 113 países entre 1950 y1982 deja lugar a pocas dudas acerca de que el crecimiento económico y la estabilidad política se determinan conjuntamente, de que esta última tiende a autorreproducirse y de que en las etapas de crecimiento económico lento aumenta la propensión a que se produzcan golpes de Estado. Como, a su vez, la inestabi-

78 Véase Espina (2000). 
lidad reduce el crecimiento, frecuentemente estas situaciones se convierten en una tram$\mathrm{pa}^{79}$. En el modelo de Bertochi y Spagat, esto implica que el coeficiente al que se eleva el tamaño relativo del grupo dos residual para calcular la probabilidad de revolución aumenta cuando lo hace la renta nacional — lo que implica que tal probabilidad desciende porque el coeficiente es inferior a la unidad-y el grupo uno se encuentra en mejor situación para aumentar la porción de cooptados al grupo $C$, de modo que el crecimiento económico actúa como un estabilizador de las crisis políticas $-\mathrm{y}$, al mismo tiempo, esa mayor estabilidad tiende a aumentar el ritmo de crecimiento, amplificando el proceso y convirtiéndolo en círculo virtuoso 80 .

\section{CONCLUSIÓN}

En el viejo mundo, la extensión del sufragio funcionó como un mecanismo de cooptación con vistas al control del conflicto social y como válvula de seguridad o dique de contención frente a las revoluciones. El proceso fue prácticamente simultáneo al que se desarrollaba en las principales ex colonias europeas, pero, aunque el calendario convergió en unos casos y divergió en otros, sus tiempos no se superpusieron. Por mucho que los contextos revolucionarios europeos tuviesen su correlato en los procesos de independencia colonial y en la configuración de las instituciones postcoloniales, la escala de tiempo de los procesos revolucionarios europeos poco o nada tuvo que ver con la de la dinámica migratoria, que era la finalidad principal de las políticas igualitarias y de la legislación de extensión del sufragio en las zonas ultramarinas.

En América, esto afectó principalmente a los países del norte, en los que la extensión del derecho al sufragio avanzó pari passu con la aplicación de políticas liberales en materia de escuela pública, tributación y acceso a la propiedad de la tierra, para atraer inmigración -y lo mismo puede afirmarse de otras colonias blancas anglosajonas-. Al mismo tiempo, el rápido avance hacia la igualdad política aparece altamente correlacionado con la igualdad económica y la escasez de mano de obra en las distintas áreas, lo que afectó también a Sudamérica, en donde el calendario de la participación efectiva en las elecciones se rigió por el hambre demográfica, de modo que los países más adelantados fueron también los que experimentaron mayor escasez de fuerza de trabajo, como Argentina, Uruguay y Costa Rica ${ }^{81}$.

\footnotetext{
79 Véase Alberto Alesina, Sule Ozler, Nouriel Roubini y Phillip Swagel (1992), p. 23 y tabla 6.

80 Ibid., passim. El trabajo establece la fuerte relación negativa entre inestabilidad política y crecimiento.

81 Véase Engerman y Sokoloff, citado, tabla 1. Sobre el nexo entre igualdad económica y La democracia en América, la referencia clásica es, otra vez, Tocqueville.
} 
En conclusión, la aplicación de las técnicas de maximización matemática al problema de elección racional al que se enfrentan las élites dirigentes tradicionales cuando sus posiciones sociales se ven contestadas por los grupos sociales subordinados y/o por las élites emergentes permite - y exige, por imperativo metodológico- delimitar mejor el tipo de revolución típicamente moderno, en el que los fines explícitos del proceso revolucionario consisten en mejorar el bienestar material e intelectual de la mayoría de la población, así como la justicia y la equidad en las relaciones sociales, culturales, políticas y económicas. Sin esta referencia a los fines -implícita, por ejemplo, en la obra de Eisenstadt-, la sociología de la revolución se limita en cierto modo a una taxonomía formalista de los grandes conflictos sociales - lo que no le resta un ápice de legitimidad teórica ni de utilidad práctica.

A partir de ella, sin embargo, el estudio de las revoluciones ocurridas en la modernidad se transforma en una rama de la sociología evolucionista del cambio social, que las analiza por relación a otras formas de cambio alternativas. Sus dos grandes variantes, la revolución liberal —con su transformación más o menos paulatina en democracia, que sólo es plena cuando se eliminan todos los obstáculos técnicos al ejercicio del derecho de voto ${ }^{82}$ y la revolución socialista, se presentan como dos propuestas generales de organización social en pugna abierta por alzarse con la victoria en el proceso de selección histórica - y, por tanto, «natural»— de las grandes formas de articulación de la vida en sociedad dentro de la civilización moderna, que significa la secularización radical de los fines sociales.

Ello permite distinguir nítidamente las revoluciones modernas de las premodernas, en las que los fines perseguidos son de carácter trascendente o teocrático, y cuya evaluación de resultados no puede realizarse en términos de elección racional porque tales fines resultan inconmensurables con los fines estrictamente mundanos vigentes en la civilización moderna. Lo mismo cabe afirmar de los conflictos —o «revoluciones»— de carácter étnico, que tiñen también algunos procesos revolucionarios autocalificados de «nacionales». Finalmente, tampoco cabe confundir las revoluciones modernas con los diferentes procesos de descolonización, que enfrentan a sujetos colectivos perfectamente delimitados que habían mantenido históricamente relaciones políticas de dominio soberano y subordinación.

82 Éste es uno de los temas de debate en Chile tras las últimas elecciones presidenciales (Wilhelm, 1999). 


\section{BIBLIOGRAFÍA}

ACEMOGLU, Daron, y ROBINSON, James A. (2000a): «Democratization or Repression?», European Economic Review, Papers and Proceedings, vol. 44, abril, pp. 683-693. Versión julio 1999 disponible en http://econ-www.mit.edu/ faculty/download_pdf.php?id=158.

- (2000b): «Why Did the West Extend the Franchise? Democracy, Inequality and Growth in Historical Perspective», Quarterly Journal of Economics, vol. 115, noviembe, pp. 1167-1199. Versión septiembre 1999 en http://econwww.mit.edu/faculty/download_pdf.php?id=150.

ALESINA, Alberto; OZLER, Sule; ROUBINI, Nouriel, y SWAGEL, Phillip (1992): «Political instability and economic growth», Journal of Economic Growth, vol. 1, n. ${ }^{\circ}$ 2, pp. 189-212, junio 1996. NBER Working Paper, n. ${ }^{\circ}$ w4173, septiembre, $h$ ttp://www.nber.org/papers/W4173.

ARTHUR, W. Brian (1997): Increasing Returns and Path Dependence in the Economy, The University of Michigan Press, Ann Arbor.

ARTOLA, Miguel (1968): La España de Fernando VII, en la Historia de España dirigida por Ramón Menéndez Pidal, vol. XXVI, Madrid: Espasa.

- (1973): La Burguesía Revolucionaria (1808-1869), Alianza.

BAERT, Patrick, y TURNER, Bryan (2004): «New Pragmatism and Old Europe. Introduction to the Debate between Pragmatist Philosophy and European Social and Political Theory», European Journal of Social Theory, 7 (3), agosto, pp. 267-274.

BAGEHOT, Walter (1872): Physics and Politics, Batoche Books, Kitchener, Ontario, 2001. Edición electrónica en http://socserv2.socsci.mcmaster.ca/ econ/ugcm/3//3/bagehot/physics.pdf. Capítulo final y síntesis: «Verifiable Progress Politically Considered» (pp. 115-125) (versión española, con mi introducción, en este mismo número de REIS).

- (1873): Lombard Street: A Description of the Money Market. Edición electrónica en http://socserv2.socsci. mcmaster.ca/ econ/ugcm/3//3/bagehot/lombard.html.

BENJAMIN, Thomas (2000): La Revolución. Mexico's Great Revolution as Memory, Myth \& History, Austin: University of Texas Press.

BERICAT ALASTUEY, Eduardo (2001): «Max Weber o el enigma emocional del origen del capitalismo», Revista Española de Investigaciones Sociológicas (REIS), n. ${ }^{\circ}$ 95, julio-sepiembre, pp. 9-36.

BERLIN, Isaiah (1956): The Age of Enlightenment, NY: Meridian, 1984.

- (1960-1990): “José de Maistre y los orígenes del fascismo», en El Fuste torcido de la humanidad, Península, 1992, pp. 103-166.

- (1965-1993): The Magus of the North. J. G. Hamann and the origins of Modern Irrationalism, NY: Farrar, Straus and Giroux, 1993.

- (1966): The Roots of Romanticism, Princeton University Press, 1999.

- (1973-1979): «The Counter-Enlightement», en Dictionary of the History of Ideas, NY: Scribner's, vol. 2, pp. 110112 (ed. esp.: Contra la Corriente, FCE, 1992, pp. 59-84).

BERTILSSON, Thora Margareta (2004): «The Elementary Forms of Pragmatism: On Different Types of Abduction», European Journal of Social Theory, 7 (3), agosto, pp. 371-389.

BERTOCCHI, Graziella (2004): Growth, History and Institutions, CEPR DP4738, noviembre. 
BERTOCCHI, Graziella, y SAPAGAT, Michael (2001): «The Politics of Cooptacion», Journal of Comparative Economics, vol. 29, diciembre, pp. 591-2007.

BORGES, Jorge Luis (1941): «La lotería de Babilonia», en Ficciones, Obras Completas, I, Emecé Editores, 1989.

BRINTON, Crane [1938]: The Anatomy of Revolution, Prentice Hall, 1965.

BROSE, Hanns-Geog (2004): «An Introduction towards a culture of non-simultaneity?», Time \& Society, vol. 13, n. ${ }^{\circ} 1$, marzo.

CARLSON, Peter (2004): «Hey, Professor, Assimilate This», The Washington Post, 9 marzo, p. C01.

COHN-BENDIT, Dany (1986): Nous l'avons tant aimé, la Révolution, Barrault.

COLOMER, Josep M. (2001): Instituciones Políticas, Barcelona: Ariel, enero.

DAY, Richard H., y WALTER, Jean-Luc (1989): «Economic growth in the very long run: on the multiple-phase interaction of population, technology, and social infrastructure», en Economic Complexity: Chaos, Sunspots, Bubbles, and Nonlinearity, Proceedings of the Fourth International Symposium in Economic Theory and Econometrics, edited by William A. Barnett, John Geweke and Karl Shell, Cambridge University Press.

DAVIES, James C. (1962): «Toward a Theory of Revolution», American Sociological Review, 27, pp. 5-19.

DOLAN, K., y SUGGET, J. (eds.) (2004): Obstacles to a Democratic Election. Reports of Electoral Problems in Key U.S. States during the 2004 Election, http://www.nov3.us/obstacles.pdf.

ECKSTEIN, Harry, y GURR, Ted Robert (1975): Patterns of Authority (Comparative Studies in Behavioural Science), John Wiley \& Sons Inc.

EISENSTADT, Shmuel N. (1978): Revolution and the Transformation of Societies, NY: Free Press.

- (1986): «The Axial Age Breakthroughs - Their Characteristics and Origins», en The Origins and Diversity of Axial Age Civilizations, S. N. Eisenstadt (ed.), State University of New York Press.

- (1996): Japanese Civilization: A Comparative View, Chicago: University of Chicago Press. Síntesis: «La experiencia histórica de Japón: la paradoja de la modernidad no axial», en http://www.unesco.org/issj/rics151/eisenstadt. htm.

- (1999): Fundamentalism, Sectarianism, and Revolution. The Jacobin Dimension of Modernity, Cambridge University Press.

- (2000): «The Civilizational Dimension in Sociological Analysis», Thesis Eleven, n. ${ }^{\circ}$ 62, August, pp. 1-21.

- (2001): «The Civilization Dimension of Modernity. Modernity as a Distinct Civilization», International Sociology, vol. 16.3, pp. 320-340.

- (2004): Interviewed by Gerard Delanty: «Pluralism and the Multiple Forms of Modernity», European Journal of Social Theory, vol. 7.3, pp. 391-404.

ENGERMAN, Stanley L., y SOKOLOFF, Kenneth L. (2005): “Colonialism, Inequality, and Long-Run Paths of Development», NBER Working Paper, 11057, enero: http://www.nber.org/papers/w11057.

ESPINA, A. (2000): «De la caída del Antiguo Régimen a la Segunda República: un enfoque neokeynesiano de la economía española», Sistema, n. ${ }^{\circ}$ 155-156 —monográfico sobre El Legado de Keynes—, abril, pp. 175-209.

- (2001a): «La resistencia a la Monarquía de España y el sistema europeo de Estados. Un ensayo de sociología histórica a modo de balance del centenario de Carlos de Gante», Sistema, n. ${ }^{\circ}$ 164, septiembre, pp. $43-67$. 
ESPINA, A. (2001b): «Crítica a Instituciones Políticas», Revista Española de Ciencia Política, n. ${ }^{\circ}$ 5, octubre, pp. 203211.

- (2005a): «Sobre la "mano invisible": valores, sentimientos morales e interés en la Inglaterra moderna», Revista de Estudios Políticos, n. ${ }^{\circ}$ 128, abril-junio, pp.129-161.

- (2005b): La colonización latinoamericana y el desarrollo económico, Real Instituto Elcano. En proceso de publicación, http://www.realinstitutoelcano.org/zonasanalisis.asp?zona=2\&version=1\&publicado=1.

FESTENSTEIN, Matthew (2004): «Deliberative Democracy and Two Models of Pragmatism», European Journal of Social Theory, 7 (3), pp. 291-306.

FORAN, John (ed.) (1995): A Century of Revolution Social Movements in Iran, University of Minnesota Press, Social Movements, Protest, and Contention Series, vol. 2.

- (1997): "Review: Social Revolutions in the Modern Worl», The American Political Science Review, vol. 91, n. $^{\circ} 1$, marzo, pp. 222-223.

GALOR, Oded, y MOAV, Omer (2003): Das Human Kapital (15 julio), Brown University Working Paper n. ${ }^{\circ} 2000-17$. http://ssrn.com/abstract=246295.

GEORGESCU ROEGEN, N. (1971): The Entropy Law and the Economic Process, Cambridge, MA: Harvard University Press (versión en español: $n .^{\circ} 3$ de la Colección Economía y Naturaleza de la Fundación Argentaria-Visor, Madrid, 1986).

GIDDENS, Anthony (1997): «Vivir en una Sociedad Postradicional», cap. 2 de U. Beck, A. Giddens y S. Lash, Modernización reflexiva. Política, tradición y estética en el orden social moderno, Alianza Universidad (1. ${ }^{\mathrm{a}}$ ed.: Blackwell, 1994), pp. 102-107.

GIESEN, Berhard (2004): «Non contemporaneity, Asyncronicity and Divided Memories», Time \& Society, vol. 13, n. ${ }^{\circ}$, marzo, pp. $27-40$.

GOLDSTONE, Jack A. (1980): «Theories of Revolution: The Third Generation», World Politics, vol. 32 , n. ${ }^{\circ} 3$ (abril), pp. 424-453.

- (2001): «Toward a Fourth Generation of Revolutionary Theory», Annual Review of Political Science, n. ${ }^{\circ}$ 4, pp. 139187.

GORBACHEV, Mikhail (2002): «Looking Back on Perestroika», lunes 11 de noviembre, Harvard University: http:// www.news.harvard.edu/gazette/2002/11.14/11-transcript.html.

GURR, Ted Robert (1968): «A Causal Model of Civil Strife: A Comparative Analysis Using New Indices», The American Political Science Review, vol. 62, n. ${ }^{\circ} 4$ (diciembre), pp. 1104-1121.

- (1974): «Persistence and Change in Political Systems, 1800-1971», The American Political Sciencie Review, vol. 68, n. $^{\circ} 3$, diciembre, pp. 1482-1504.

- (1994): «Peoples Against States: Ethnopolitcal Conflict and the Changing World System», 1994 Presidential Address (ISA), International Studies Quarterly, vol. 38, n. ${ }^{\circ} 3$ (septiembre), pp. 347-377.

HENDERSON, Errol A. (2004): «Mistaken Identity: Testing the Clash of Civilizations Thesis in Light of Democratic Peace Claims», British Journal of Political Science, 34, pp. 539-563.

HILL, Christopher (1996): «Gerard Winstanley: 17th Century Communist at Kingston», http://www.kingston.ac.uk/ cusp/Lectures/Hill.htm.

HIRSCHMAN, Albert O. (1992): Rival Views of Market Society, and Other Recent Essays, Harvard University Press. 
HIRSCHMAN, Albert O. (1993): «Exit, Voice, and the Fate of the German Democratic Republic: An Essay in Conceptual History», World Politics, 45 (2), pp. 173-202. En alemán: Leviathan, 20 (3), 1992, pp. 330-358 (traducción al español en Claves).

HOFSTADTER, Richard (1944): Social Darwinism in American Thought, Paperback edition revised, Boston: Beacon Press, 1955 (vv.ee.).

HUNTINGTON, Samuel (1993): «The Clash of Civilizations», Foreign Affairs, vol. 72.3, pp. 22-28.

- (1996): The Clash of Civilizations and the Remaking of the World Order, Simon and Schuster.

KALDOR, Mary (2005): «La guerra equivocada de Irak», El País, domingo 24 de julio.

KASPEREN, Lars Bo (2004): «How Denmark Became Democratic. The Impact of Warfare and Military Reforms», Acta Sociologica, vol. 47 (1), pp. 71-89.

KURAN, Timur (1991): «Now Out of Never: The Element of Surprise in the European Revolution of 1989», World Politics, vol. 44, n. ${ }^{\circ}$, octubre, pp. 7-48.

KURZ, Karin (2004): «Labour Market Position, Intergeneration Transfers and Home-ownership. A Longitudinal Análisis for West German Birth Cohorts», European Sociological Review, vol. 20, n. ${ }^{\circ}$ 2, abril, pp. 141-159.

LAZARE, Bernard (1894): L'antisémitisme, son histoire et ses causes, París: Léon Chailley (versión española, con mi introducción, en MTSS, Clásicos, 1986).

LAZAREV, Valery (2002): «Elite circulation and political stability in the Soviet Union», Governments and Institutions in Twentieth Century European Economic History, Summer Research Euro-Workshop 2002 Papers, University of Warwick, Economics Department, en http://www2.warwick.ac.uk/fac/soc/economics/news/2002/summer2002/papers/ lazarev.pdf.

LICHBACH, Mark I.; DAVENPORT, Christian, y ARMSTRONG II, David A. (2004): "Contingency, Inherency, and the Onset of Civil War», Unpublished Manuscript, University of Maryland, Draft Diciembre 9, 2003: http://www.bsos.umd. edu/gvpt/davenport/cioc.pdf (en Internet: 6 junio 2005); versión Septiembre 20, 2004: http://www.yale.edu/ycias/ ocvprogram/Davenport.pdf.

LIVELY, Jack (1965): «Introduction» a The works of Joseph de Maistre, Londres: Allen \& Unwin.

MANNHEIM, Karl (1936): Ideology and Utopia, Routledge \& Kegan (edición española: Aguilar, 1966).

MAISTRE, Joseph de (1797): Considerations sur la France, cap. I: «Des révolutions». Edición electrónica: http://cage. ugent.be/ dc/Literature/JMCF/JMCF01.htm/ (a partir de la edición de 1844).

MARANGOS, John (2005): «A Political economy approach to the neoclassical gradualist model of transition», Journal of Economic Surveys, vol. 19, n. ${ }^{\circ}$ 2, pp. 263-293.

MOORE, Barrington, Jr. (1955): «Notes on the Process of Adquiring Power», World Politics, vol. 8, n. $^{\circ} 1$ (octubre), pp. 1-19.

- (2000): Moral Purity and Persecution in History, Princeton University Press.

PALMA, Giuseppe di (1991): «Legitimation from the top to Civil Society: Politico-Cultural Change in Eastern Europe», World Politics, vol. 44, n. $^{\circ} 1$ (octubre), pp. 49-80.

PARETO, Vilfredo (1935): The Mind and Society, ed. Arthur Livingston (trad. Andrew Bongiomo), New York: Harcourt, Brace \& Co.

RAY, Larry (2004): «Pragmatism and Critical Theory», European Journal of Social Theory, 7 (3), pp. 307-321. 
SHWEDER, Richard A. (2004): «The Idea of Moral Progress: Bush versus Posner versus Berlin», conferencia. Síntesis en «George W. Bush \& the missionary position», Daedalus, verano, pp. 27-36.

SKOCPOL, Theda (1979): States and Social Revolutions: A Comparative Analysis of France, Russia and China, Cambridge University Press.

- (1997): Social Revolutions in the Modern World, CUP, 1994, Series: Cambridge Studies in Comparative Politics.

SMELSER, Neil (1963): Theory of Collective Behavior, Free Press.

SOROKIN, Pitirim A. [1925]: The sociology of revolution, New York, NY: Howard Fertig, Inc. (1967).

- (1937): Social and Cultural Dynamics: Fluctuation of Social Relationships, War and Revolution, Allen \& Unwin Ltd.

SPENCER, Herbert (1852): «A theory of population, deduced from the general law of animal fertility», The Westminster Review, vol. 57, pp. 468-501. Síntesis en http://www.fordham.edu/halsall/mod/spencer-darwin.html.

- (1857): «Progress: Its Law and Causes», The Westminster Review, vol. 67 (abril), pp. 445-485. Síntesis en http://www. victorianweb.org/philosophy/spencer/dagg2.html.

- [1922]: Ceremonial Institutions, vol. 2, parte 4, de The Principles of Sociology, 3 vols., Londres: Williams \& Norgate, 1879 (algunos artículos publicados previamente en Fortnightly Review). Traducción española, citada: Instituciones Políticas, La España Moderna, Madrid.

SUMNER, William Graham (1911): «The Conquest of the United States by Spain», en War and Other Essays, New Haven: Yale University Press. Versión española, con mi introducción, en este mismo número de REIS.

SWEDBERG, Richard (1991): Schumpeter: A Biography, Princeton UP.

SZTOMPKA, Piotr (1995): Sociología del Cambio social, Madrid: Alianza Universidad Textos.

TILLY, Charles (1975): «Revolutions and Collective Violence», en F. Greenstein y N. Polsby (eds.), Handbook of Political Science, III, Reading, Mass.: Addison-Wesley.

— (1978): From Mobilization to Revolution, New York: McGraw-Hill.

- (1979): «Review: Revolution and the Transformation of Societies: A Comparative Study or Civilizations», The American Historical Review, vol. 84, n. ${ }^{\circ}$, abril, pp. 412-413.

- (1997a): «Now Where?», mayo, Draft epilogue: George Steinmetz (ed.), State/Culture: State Formation after the Cultural Turn (Cornell University Press), 1999, http://www.sociology.columbia.edu/people/faculty/tilly/papers/ now_where.html.

- (1997b): «Social Movements as Political Struggle», julio, borrador de artículo para la Encyclopaedia of American Social Movements, en preparación por Oxford University Press. http://www.sociology.columbia.edu/people/faculty/ tilly/papers/social_movements.html.

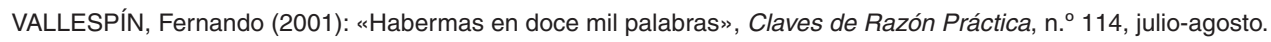

WILHELM, P. Ricardo (1999): «Inscripción automática y votación voluntaria, un cambio a la Carta Constitucional», http://www.electoral.cl/estudios/inscripcion_obligatoria_rocardo.htm/ (12 junio 2005).

WIRTH, Uwe (1998): «What is Abductive Inference?», en Encyclopaedia of Semiotics, Paul Bouissac (ed.), Oxford University Press, Lemma: «abductive inference».

- (1999): «Abductive reasoning in Peirce's and Davidson's account of interpretation», en Transactions of the Charles Sanders Peirce Society, winter 1999: S. 115-128 [versión española en C. S. Peirce y la Abduccción, Analogía Filosófica, XII/1 (1998), pp. 113-124; http://user.uni-frankfurt.de/ wirth/index.htmI]. 


\section{ABSTRACT}

This article reviews the sequence of the four «generations» of sociological theories of revolution, considering it as a process of historical-natural selection of the knowledge best adapted to its object. The modern revolution is presented, in turn, as the process of evolutionist social change par excellence (according to Jaspers and Eisenstadt). Societies, without any determinism, historically select through it the types of social organization —or «varieties», according to Bagehot - that best contribute to the progress of civilization, this latter defined as post-axial age. The transformation of the axial impulse towards transcendency explains the cathartic nature of modern revolutionary processes and makes it possible to distinguish them from pre-modern revolutions and other formally similar processes. Lastly, the rational choice model makes it possible to view the three main types of modern revolution — liberal, socialist and democratic - under the same analytical prism, where the three revolutionary «varieties» appear at the same time as alternatives and as successive options, all of them competing with the paretian model of the circulation of élites, which is also of a strictly evolutionist nature.

Key words: Revolution, Evolutionism, Social Change, Circulation of the Elites, Sociology of Time, Rational Choice. 